First Draft: January 24, 2011

Revised: December 12, 2011

\title{
Success-Driven Skill Inferences and Financial Crises
}

by

Anjan V. Thakor*

JEL Classification Numbers: G2, E32, D83

Keywords: financial crisis, learning, experience-based beliefs

Acknowledgment: I thank Elena Carletti, David Levine, Yiming Qian, and participants at seminars at the European University Institute (Florence, October 2011) the University of Iowa (November 2011), the University of Pittsburgh (December 2011), and Southern Methodist University (December 2011) for helpful comments. I alone am responsible for any errors.

*ECGI and John E. Simon Professor of Finance, Olin School of Business, Washington University in St. Louis. 


\title{
Success-Driven Skill Inferences and Financial Crises
}

\begin{abstract}
This paper develops a theory of financial crises that explains why crises should be expected to follow periods of sustained banking profitability. When there is some probability that outcomes are purely exogenous and some probability that they are driven by the talent/skill of the agents managing the assets that are associated with these outcomes, periods of sustained profitability for banks cause all agentsbanks as well as those who monitor and fund banks - to revise upward their estimates of the skill of bankers to manage risks. All agents consequently become sanguine about the consequences of bank risktaking, and banks invest in increasingly riskier assets. Further, as the number of banks entering this market grows, the liquidity of highly risky assets improves, making it more attractive for others to enter the market. The economy thus ends up with a large number of financial institutions investing in very risky assets that are traded in highly liquid markets. Subsequently, if it is revealed in some period that loan repayment probabilities are exogenous rather than skill dependent, investors rush to withdraw funds, market liquidity dries up, and a crisis ensues. The model also explains why the economy may not recover even after the friction that precipitated the crisis has dissipated. Empirical predictions and policy implications of the analysis are discussed. The analysis suggests that the majority of regulations put in place in response to the crises of the last few decades, including the recent financial crisis, may do little to prevent future crises.
\end{abstract}




\section{Success-Driven Skill Inferences and Financial Crises}

"Until 2007 we were living in a period often described as the "Great Moderation." The world economy was growing vigorously, macroeconomic indicators were significantly less volatile and, most importantly, inflation was low. Financial markets were performing strongly. Many asset prices were rising, while volatilities and risk premia were exceptionally low. Profitability in the financial sector was high, and banks seemed liquid and well capitalized...

Also, we all know today, the turmoil erupted in August 2007 when investors around the world faced a dramatic change in liquidity conditions, and it became increasingly difficult for banks to finance themselves in the wholesale money market."

Jean-Claude Trichet, President of the ECB at the Fifth ELB Central Banking Conference

Frankfurt am Main

November 13, 2008

\section{INTRODUCTION}

Financial crises have occurred throughout history (see Kindleberger (1978)). And because they have significant real consequences (see Boyd, Kwak and Smith (2005), and Reinhart and Rogoff (2008)), they have always represented a compelling phenomenon to study. But no crisis since the Great Depression has stirred the cauldron of ideas as vigorously as the recent sub-prime crisis. Perhaps because of the unfamiliar nature of the transmission mechanisms by which it spread and the surprising suddenness with which it deepened, this crisis has caused many to question the very foundations of economic models (e.g. Cabellero (2010)), a sentiment captured quite aptly in the pithy headline of a front-page article in The Wall Street Journal: “Economists’ Grail: A Post-Crash Model” (see Whitehouse (2010)).

Much of the soul-searching generated by the recent crisis is attributable to the many perplexing stylized facts related to the crisis that are difficult to square with existing theories. First, the crisis followed a long period of high profitability and growth for the financial sector. Second, there was little warning of the onset and severity of the crisis from any of the so-called "watch dogs" of the financial system - rating agencies, regulators and the creditors of financial institutions - who exhibited no public objection to the portfolio choices of financial institutions. Third, the system was flush with liquidity prior to the crisis but then liquidity seemed to dry up quickly. And finally, subsequent to the onset of the crisis, there were outcries about the underpricing of risk and widespread condemnation of "excessive risk- 
taking" by financial institutions. In particular, it was argued that these institutions were intent on taking socially-inefficient tail risks because of the protection of de facto government safety nets that arises from alleged regulatory reluctance to allow large and interconnected financial institutions to fail. There has also been criticism of regulators who did not regulate (e.g. Barth, Caprio and Levine (forthcoming)). Yet, prior to the crisis, there was little discussion that pointed at the ubiquity of elevated risk-taking and the complicity of regulators, and the manner in which these would lead to a crisis of this magnitude. In fact, it is easy to find evidence to the contrary. During 2004-07, the period leading right up to the crisis, the IMF reported that individual financial institutions were sound. The Independent Evaluation Office (IEO) of the IMF (2011) recently criticized the IMF for this, saying: "It finds that the IMF provided few clear warnings about the risks and vulnerabilities associated with the impending crisis before its outbreak."

Why do financial crises occur, why do they typically follow economic booms, and why does risktaking tend to be underpriced by all concerned - banks, regulators and investors - prior to the beginning of crises? These are the three main questions addressed in this paper. While there is a large literature on financial crises that has provided numerous valuable insights into the causes of crises (e.g., DeJonghe (2010), Wagner (2010), and the overview papers of Allen and Gale $(2007,2008)$ and Rochet (2008)), as well as desirable regulatory reform (e.g. Acharya, Cooley, Richardson and Walter (2011)), the recent crisis has suggested the need for additional research.

The prevailing wisdom appears to be that this crisis was caused by misaligned incentives that encouraged reckless risk-taking by financial institutions (e.g., Bebchuk and Fried (2010), and Litan and Bailey (2009)) and lax oversight by regulators (e.g. Barth, Caprio and Levine (forthcoming) $)^{2}$ whose

\footnotetext{
${ }^{1}$ The report further states: "The banner message was one of the continued optimism after more than a decade of benign economic conditions and low macroeconomic volatility... The belief that financial markets were sound and that large financial institutions could weather any likely problem lessened the sense of urgency to address risks or to worry about the possible severe adverse outcomes."

${ }^{2}$ The reliance on moral hazard to explain financial crises is a recurring theme. For example, the savings and loan (S\&L) crisis in the 1980s was preceded by explosive growth in S\&L balance sheets and what has been characterized as excessive term-structure and credit risk that then led to the implosion of the industry. Much blame was placed in that crisis too on "greedy bankers" who supposedly exploited the government safety net and regulators who let them (e.g. Kane (1990)).
} 
incentives were not aligned with those of the taxpayers ${ }^{3}$, with fuel being added to the fire by misguided politicians whose over-zealous embrace of unregulated markets blocked regulation (e.g. Stiglitz (2010)).

Indeed, this is also the principal theme in the recently-released report of the U.S. government's Financial Crisis Inquiry Commission (FCIC), which reviewed millions of pages of documents, interviewed more than 700 witnesses and held 19 days of public hearings. ${ }^{4}$

While misaligned incentives have played an obviously important role in generating financial crises, in this paper I offer an alternative explanation that helps shed some light on various puzzling stylized facts related to the recent crisis and previous crisis. The differences between the predictions of this approach and those emerging from the misaligned incentives approach, as well as differences in regulatory policy implications, are explained later.

I propose that crises are caused by rational learning. Imagine an economy in which there is a high probability that outcomes are influenced by the a priori unknown skills of financial institutions and a small probability that these outcomes are purely exogenous. In this setting, if there is a sufficiently long sequence of good outcomes, all agents - financial institutions as well as the investors who provide funding for these institutions - believe that there is a high likelihood that financial institutions are skilled and thus capable of managing risk. This then leads financial institutions to invest in these high-return, high-risk products. The increased market entry resulting from this means that there are more institutions that are potential buyers of a bank's loans; this provides enhanced liquidity to the market for high-risk assets and makes this market even more attractive for other institutions to enter. Then, at some future date, if investors learn that the default risk in these high-risk products is truly exogenous and not skill dependent, liquidity dries up suddenly and a crisis commences with little warning.

\footnotetext{
${ }^{3}$ This is similar to the incentive conflicts between regulators and taxpayers discussed by Kane (1990), and analyzed formally in a career-concerns setting by Boot and Thakor (1993).

${ }^{4}$ The report claims that industry players and government regulators saw warning signs of the impending crisis, but chose to ignore them. It blames the Federal Reserve for being too supportive of industry growth objectives (e.g., Federal Reserve governor Edward Gramlich, in 2004, "We want to encourage growth in the subprime lending market"). The report also criticizes credit rating agencies as well as "More than 30 years of deregulation and reliance on self-regulation by financial institutions, ...".
} 
This explanation for financial crises is consonant with the stylized facts related to the subprime crisis that were discussed earlier. More importantly, it illuminates the difficulty of avoiding crises in certain settings even if incentives are properly aligned, and points to how appropriate regulatory responses should be assessed.

In this model, a prolonged period of favorable outcomes invariably leads financial institutions to invest in riskier, higher-return assets. This then increases the probability of a crisis. After the crisis, financial institutions retreat to safer assets and a (possibly long) period of modest but positive profitability follows, which then sows the seeds for the next crisis. That is, this paper provides a theory of "crisis cycles".

The model helps explain that crisis cycles occur even if bankers are not seeking excessive risks to exploit government safety nets. Moreover, regulatory initiatives like attempts to control bank risk-taking through limits on executive pay or direct monitoring are unlikely to be effective in preventing crises because, like bank executives, "watch dogs" like regulators and rating agencies also revise upward their beliefs about bank risk-management skills subsequent to long periods of good performance. In fact, the theory suggests that the majority of regulations - including explicit risk-sensitive pricing of government safety nets, restrictions on regulatory forbearance, and regulatory monitoring of systemic risk - and attempts to more closely align the interest of regulators and taxpayers are unlikely to significantly reduce the likelihood of future crises. I argue that countercyclical capital requirements may be one way to diminish risk taking and hence the likelihood of crises.

In addition to the puzzling facts related specifically to the recent financial crisis summarized above, the theory also helps to understand the following stylized facts related to many financial crises:

- why banks tend to keep capital levels prior to crises that seem "too low" ex post after the crisis has occurred and why risk managers are often ignored within their own institutions prior to crises;

- why the asset markets in which banks operate are flush with liquidity prior to a crisis, but this liquidity vanishes upon the onset of the crisis; 
- why bank CEOs are paid relatively high levels of compensation prior to crises and they appear to make risky bets that contribute to those crises; and

- why bank regulators seem to be lax in monitoring banks prior to crises.

In addition to better comprehending the causes of crises, we also need to improve our understanding of the after-effects. Specifically, why does the economy fall to pieces after a financial crisis? In his paper with this question as the title, Hall (2010) observes that while existing macroeconomic models account successfully for the immediate effects of a financial crisis on output and employment, they cannot explain why GDP and employment failed to recover in the recent and prior major financial crises as soon as the crisis-related financial frictions had returned to normal. In an extension of the model, I show why bank lending and hence the real economy may not recover for a while even after the financing friction - sudden loss of liquidity for banks - that precipitated the crisis has subsided. The intuition for this result is that a crisis can lead banks to lower their assessments of their own abilities so much that they may be averse to even investing in relatively low-risk assets. Bank lending/investment thus freezes up even though investors are willing to fund banks. ${ }^{5}$

This paper is related to the large and growing literature on financial crises (e.g., Allen and Carletti (2006, 2007), Allen and Gale (2000a, 2000b), and Boyd, Kwak and Smith (2005), in addition to the papers cited earlier). Recent papers have focused on the role of complexity and innovation. Allen, Babus and Carletti (2010) develop a model in which networks arise because banks swap projects to diversify individual risks and thereby become interconnected. This can then generate systemic risk. Caballero and Simsek (2010) show that growth in financial networks causes endogenous complexity to increase. The increased complexity faced by banks may cause liquidity to vanish and a crisis may come about. Other papers have focused on the role of financial innovation. Gennaioli, Shleifer and Vishny (forthcoming) have proposed that "neglected risk" in innovative financial products, when joined with limited supply of traditional safe products, results in excess demand for innovative products. When the neglected risks are

\footnotetext{
${ }^{5}$ This problem is exacerbated if investors have not raised their assessments of managerial abilities, since in this case the crisis-precipitating financing friction may still remain.
} 
realized, investors dump these innovative products, causing banks to be stuck with them. Shleifer and Vishny (2010) focus on securitization and argue that it leads to excessive leverage and lending. Thakor (forthcoming) shows that potential disagreement about the profitability of an innovation acts as an endogenous barrier to entry and entices banks to pursue the innovation. However, this disagreement may also cause investors to withdraw funding, leading to a crisis.

In contrast to these papers, the focus in this paper is not on complexity or innovation. The assets available to financial institutions are known at the outset and there is no disagreement over their profitability. Moreover, unlike the existing literature, the focus here is on explaining why financial crises should be expected to follow economic booms and periods of sustained banking profitability and why risk is seemingly "underpriced" just prior to the onset of crises. The central idea in this paper, and one that has not been previously examined as a causal factor in financial crises, is that experience-based learning, whereby outcomes are attributed to skill but have a non-zero probability of being viewed in the future as being skill-independent, can create an environment for banks to take successively higher levels of risk That is, after a sequence of favorable outcomes, estimates of bank skill are elevated and their ability to manage risk is perceived to be high. The consequence is greater risk-taking and possibly crises, even without incentive misalignment.

In what follows, I present the analysis in three parts. The first part shows how financial crisis can arise in a simple learning model, with no loan resale market. The model is developed in Section II and this analysis is presented in Section III. In the second part, I introduce a market in which banks can sell loans to each other. The main purpose is to show that this market is a double-edged sword. On the one hand, it increases the liquidity of the loans banks hold, thereby reducing the likelihood of a crisis ex post after a liquidity shock hits. On the other hand, it actually makes it more attractive for banks to invest in riskier assets, which increases the ex ante likelihood a crisis. This analysis appears in Section IV. The third part of the analysis, which appears in Section V, discusses how the model can be used to generate a theory of crisis cycles, and how it leads to an explanation of why the economy tends to fall to pieces after 
a crisis. This section also includes a discussion of the interpretations and regulatory policy implications of the analysis. Section VI concludes. All proofs are in the Appendix.

\section{THE BASIC MODEL}

This section describes the basic model without a loan resale market. I begin with a description of agents and preferences. I then discuss the sequence of events, followed by the investment opportunity set. This is followed by a statement of the observability assumptions and description of how beliefs are revised. I conclude with a summary of the timeline.

\section{A. Agents and Preferences}

The key players in the model are financial intermediaries and investors who provide financing for these intermediaries. The liabilities of the intermediaries are uninsured ${ }^{6}$, so even though I will refer to these intermediaries as "banks" henceforth, it should be understood that they encompass a broad array of financial intermediaries that raise their funding in the capital market, such as investment banks and commercial banks.

There is universal risk neutrality and the riskless rate of interest is zero.

\section{B. Sequence of Events: Agents, Information Signals and Loan Resale Market}

Sequence of Events: There are five payoff-relevant dates: $t=0,1,2,3$ and 4 that cover two time periods over which bank operate. At $t=0$, there are $N_{0}$ banks in the market. Each bank can choose to invest $\$ 1$ at $t=0$ in either a prudent loan $(P)$ or a risky loan $(R)$. Both loans mature at $t=2$. For simplicity, the entire $\$ 1$ is raised at $t=0$ in the form of (uninsured) debt financing in the capital market. The debt is short-term in nature, so investors have the option to withdraw funding at $t=1$ if they wish, or continue to keep their funding with the bank and be paid off at $t=2$. The repayment promised to investors differs based on whether they withdraw at $t=1$ or $t=2$. This short-term (demandable) nature of debt financing,

\footnotetext{
${ }^{6}$ The model goes through with partially insured liabilities.
} 
which creates a maturity mismatch on the bank's balance sheet, is just taken as a given here, because the economic rationale for it is well known (see, for example, Calomiris and Kahn (1993)).

\section{Investment Opportunities: P and R Loans}

The bank chooses at $t=0$ and then again at $t=2$ between loans $P$ and $R$, a mutually-exclusive set of loans.

P Loans: Loan $P$ is either $\operatorname{good}(G)$ or bad $(B)$ but no one can determine for sure a priori whether the loan is $G$ or $B$. A loan of type $G$ loan pays off $X_{p}>1$ w.p. 1 , and a $B$ loan pays off $X_{p}$ w.p. $b \in(0,1)$ and 0 w.p. $1-b$.

It is commonly believed at $t=0$ that there are two possible states of nature in any given period. In one state (probability $\lambda \in(0,1)$ ), the probability that the loan is type $\mathrm{G}$ is purely exogenous and fixed at $r \in(0,1)$. In another state (probability $1-\lambda)$, the probability that the loan is type G depends on the skill/talent of the bank in monitoring the loan after it is made. ${ }^{7}$ There are two possible types of banks: talented $(\tau)$ and untalented $(u)$. A type- $\tau$ bank monitors the $P$ loan with perfect efficiency and is thus able to ensure that the loan is $G$ w.p. 1. A type- $u$ bank, however, has no monitoring ability and thus ends up with a $B$ loan w.p. $1 .^{8}$ The common prior belief at $t=0$ is that the probability that any given bank is type- $\tau$ is $r$, and the probability that it is type $u$ is $1-r$.

For the first period (pertaining to the loans made at $t=0$ ), it becomes common knowledge at $t=1$ whether the probability of the loan being type $G$ is purely exogenous or it depends on the skill/talent of the bank. For the second period (loans made at $t=2$ ), this information arrives at $t=3$. On any given

\footnotetext{
${ }^{7}$ This specification of the model attempts to capture "model uncertainty". In reality, investors can never be certain about the extent to which asset payoffs are influenced by the monitoring or screening skills of bankers. There may, however, be indications of the true model of the world that investors receive in the form of noisy signals. For example, prior to the subprime crisis, investors may have believed that there was a non-zero probability that the skill of bankers in selecting the appropriate loans for securitization portfolios would work with diversification to make the probability of losses for the AAA-rated tranches arbitrarily close to zero. But there was also some non-zero probability that bankers' skills could not affect loss probabilities.

${ }^{8}$ This assumption is merely to reduce notational clutter, and one could assume instead that a type-u bank ends up with a B loan w.p. less than 1
} 
period, the realization of this uncertainty applies to $P$ loans made by all banks, but across the two periods, these state variables are identically and independently distributed (i.i.d.) random variables. That is, the realization of this uncertainty in the first period does not provide any new information about the likelihood of a particular realization in the second period.

$$
\begin{aligned}
& \text { At } t=0 \text { then, the prior belief about the probability of success of the } P \text { loan at } t=2 \text { is } \\
& r_{o}^{P} \equiv r+[1-r]^{b}
\end{aligned}
$$

It is assumed that

$$
r_{o}^{P} X_{p}>1
$$

So $P$ is a socially-efficient asset given these prior beliefs.

However,

$$
b X_{p}<1
$$

So a bank known to be type- $u$ almost surely (in the state in which the probability of having a type- $G$ loan is still dependent) would never be able to raise financing for a $P$ loan.

R Loans: The $R$ loan can be either $\operatorname{good}(\hat{G})$ or bad $(\hat{B})$. No one can determine a priori whether a given loan is $\hat{G}$ or $\hat{B}$. A loan of type $\hat{G}$ pays off $X_{R}$ w.p. $q \in(0,1)$ and 0 w.p. $(1-q)$, whereas a $\hat{B}$ loan pays off 0 w.p. 1 . It is assumed that the $\hat{G}$-type $R$ loan is better than the $G$-type $P$ loan, i.e.,

$$
q X_{R}>X_{P}
$$

As in the case of the $\mathrm{P}$ loan, there are two possible states of nature with the $\mathrm{R}$ loan in any given period. With probability $\lambda$, the probability is exogenously fixed at $r$ that the loan is type $\hat{G}$, and with probability $1-\lambda$, the probability that the loan is type $\hat{G}$ is dependent on the bank's monitoring skill. In this case, the common belief is that a type- $\tau$ bank will be able to ensure w.p. 1 that it is a $\hat{G}$ loan, whereas a type- $u$ bank will ensure w.p. 1 that it is a $\hat{B}$ loan. 
It will also be assumed, for later use, that the difference in loan repayment (success) probabilities across the good and bad loans is greater for the $R$ loan than the $P$ loan, i.e.,

$$
q>1-b
$$

This is motivated by the observation that $R$ is a more complex loan for which the importance of the bank's skill/talent is greater for such a loan than for $P$.

At $t=0$ then, the prior probability of success of the type $\mathrm{R}$ loan at $t=2$ is:

$$
r_{o}^{R} \equiv r q
$$

and it is assumed that

$$
r_{o}^{R} X_{R}<1
$$

so the $\mathrm{R}$ loan is socially inefficient given the prior beliefs.

A summary of these loans and payoffs is provided in the table below.

Table 1: Loan Payoffs

\begin{tabular}{|c|c|c|}
\hline & Type \& success probability: & Date 2 payoff: \\
\hline $\mathrm{P}$ & $G$ w.p. $\mathrm{r}$ & $\mathrm{X}_{\mathrm{p}}>1$ w.p. 1 \\
\hline & & $\mathrm{X}_{\mathrm{p}}$ w.p. b \\
& $B$ w.p. 1-r & 0 w.p. 1-b \\
\hline & & $\mathrm{X}_{\mathrm{R}}>1$ w.p. $\mathrm{q}$ \\
$\mathrm{R}$ & $\hat{G}$ w.p. $\mathrm{r}$ & 0 w.p. 1-q \\
\hline & $\hat{B}$ w.p. 1-r & 0 w.p. 1 \\
\hline & $\hat{B}$ w.p. 1 & 0 w.p. 1 \\
\hline
\end{tabular}

\section{Observability and Knowledge Assumptions}

Each bank's loan choice at any given date is commonly observable. So, investors know the bank's choice $(P$ or $R)$ before providing financing. Also publicly observable is whether the bank's loan repaid or defaulted at the end of the period ( $t=2$ for the first period and $t=4$ for the second period) $t=1$ (and then at $t=3$ ), all agents observe whether the loan success probability is exogenous or dependent on bank skill. 


\section{E. Capital Market Financing}

Investors provide financing in a competitive capital market, so that bank debt is priced to yield investors an expected return of zero. If investors liquidate a loan at $t=1$ or $t=3$, they collect $L \in\left(r q X_{R}, 1\right)$.

\section{F. Summary of Timeline}

At $t=0$, there are $N_{0}$ banks. Each bank chooses to invest $\$ 1$ in either a prudent $(P)$ loan or a risky $(R)$ loan. Each loan is entirely funded by short-term, uninsured debt and each matures at $t=2 .{ }^{9}$ At $t=1$, it becomes known whether the bank's ability to invest in a good loan is exogenously fixed or dependent on the bank's skill. Based on this revelation, investors who funded the bank at $t=0$ may wish to withdraw their funding at $t=1$. In this event, the bank must liquidate. A bank that suffers a withdrawal of funding by investors at $t=1$ will continue to exist (and thus have the opportunity to make a second-period loan) if it pays investors the market price of their debt, and ceases to exist otherwise (liquidation). If the bank survives until $t=2$ without loan resale, then it collects its loan payment (if available) and pays off investors. The lending cycle then restarts at $t=2$ and the bank makes a new choice of loan and funds it entirely with new (short-term) debt. Any positive profit at $t=2$ on the first-period loan is paid out as a dividend to the bank's shareholders. ${ }^{10}$ The date-1 signal about whether the success probability of the oan is skill-dependent or purely exogenous is repeated at $t=3$. The terminal payoff is realized at $t=4$.

A pictorial summary of the sequence of events is provided in Figure 1.

Figure 1 goes here

\section{ANALYSIS OF THE BASIC MODEL}

My main goal in this section is to analyze the model developed in the previous section to show how financial crises - that have many of the features discussed in the previous section - can arise.

\footnotetext{
${ }^{9}$ It makes little difference to the analysis if the bank was partly financed with equity, as long as it is not predominantly financed with equity. Non-trivial amounts of debt financing are essential for fragility.

${ }^{10}$ This is for simplicity. If the bank could use its first-period profit to fund part of its second-period loan, it would reduce the reliance on outside debt. However, the analysis is qualitatively unchanged if the bank has to fund the loan even partly from outside debt.
} 


\section{A. Analysis of Outcomes at $t=2$}

In the usual backward induction manner, I start by analyzing the second period, beginning at $t=2$, first and then the first period beginning at $t=0$.

Default/Repayment on First-Period Loan: Suppose the bank made a $P$ loan at $t=0$. There are now two possible states for the bank at $t=2$; (i) its loan defaults at $t=2$, or (ii) its loan pays off.

State (i): Repayment Failure (P loan defaults at $t=2$ ): In this case, the common posterior beliefs about the bank's type is (assuming that it was revealed that the loan repayment probability is skill dependent):

$$
\begin{aligned}
r_{2}^{f} & =\operatorname{Pr}(\tau \mid \text { default on first-period loan }) \\
& =0 .
\end{aligned}
$$

If at $t=1$, it was revealed that the loan success/repayment probability is exogenous (this event has probability $\lambda$ ), then the posterior belief about the probability of second-period success for a $P$ loan at $t=2$ is:

$$
r_{2}^{P}(f)=r_{o}^{P}=r+b[1-r]
$$

and the posterior belief about the probability of second-period success for an $R$ loan at $t=2$ is:

$$
r_{2}^{R}(f)=r_{o}^{R}=r q
$$

To understand (9) and (10), note that if the loan success probability is revealed at $t=1$ to be exogenously fixed, then the posterior belief stays at the prior belief. Looking ahead to the second period, with probability $\lambda$ the posterior belief at $t=3$ will be the same as $r_{o}^{P}$ or $r_{o}^{R}$, and with probability $1-\lambda$ the posterior belief at $t=3$ will be revised based on what is revealed at that time about the bank's skill. However, since beliefs form a (Doop) martingale, the expected value of this posterior belief at $t=3$ equals the prior belief at $t=2$, which is $r_{o}^{P}$ or $r_{o}^{R}$. Hence, $r_{2}^{P}(f)=\lambda r_{o}^{P}+[1-\lambda] r_{o}^{P}=r_{o}^{P}$, and $r_{2}^{R}(f)=\lambda r_{o}^{R}+[1-\lambda] r_{o}^{R}=r_{o}^{R}$

Given (2), (7), (9), and (10), an immediate implication is that in this case, the bank will be able to invest only in a $P$ loan in the second period. 
However, if it is revealed at $t=1$ that the loan success probability is skill-dependent (this event has probability $1-\lambda)$, then using (8), the posterior belief at $t=2$ about the probability of second-period success for a $P$ loan (at $t=4)$ is:

$$
\hat{r}_{2}^{P}(f)=\lambda r_{o}^{P}+[1-\lambda]^{b}
$$

and the posterior belief about the probability of second period success for an $R$ loan (at $t=4)$ is:

$$
\hat{r}_{2}^{R}(f)=\lambda r_{o}^{R}
$$

It will be assumed that $\lambda$ is small enough to ensure that

$$
\left\{\lambda r_{o}^{P}+[1-\lambda] b\right\} X_{P}<1
$$

Recall that $b X_{P}<1$ (by (3)), so (13) will hold for $\lambda>0$ small enough. This implies that if the bank's first-period P loan does not repay at $t=2$, it cannot make either a $P$ loan or an $R$ loan in the second period.

State (ii): Repayment Success (P loan repaid at $t=2$ ): Now, if at $t=1$, it was revealed that the loan success probability is exogenous, then the posterior belief about the probability of second-period success for a $P$ loan at $t=2$ is:

$$
r_{2}^{P}(s)=r_{2}^{P}(f)=r_{o}^{P}
$$

and the posterior belief about the probability of second-period success for an $\mathrm{R}$ loan (at $t=4)$ is:

$$
r_{2}^{R}(s)=r_{2}^{R}(f)=r_{o}^{R} .
$$

However, if it is revealed at $\mathrm{t}=1$ that the loan success probability is skill-dependent (this event has probability $1-\lambda)$, then the common posterior belief about the bank's type is:

$$
\begin{aligned}
r_{2}^{s} & =\operatorname{Pr}(\tau \mid \text { first-period loan repaid }) \\
& =\frac{r}{r+b[1-r]}>r .
\end{aligned}
$$

The posterior belief at $t=2$ about the probability of second-period success for a $P$ loan $($ at $t=4)$ is:

$$
\hat{r}_{2}^{P}(s)=\lambda r_{o}^{P}+[1-\lambda]\left\{r_{2}^{s}+\left[1-r_{2}^{s}\right] b\right\}
$$

and the posterior belief at $t=2$ about the probability of second period success for an $\mathrm{R}$ loan (at $t=4)$ is: 


$$
\hat{r}_{2}^{R}(s)=\lambda r_{o}^{R}+[1-\lambda] q r_{2}^{s}
$$

It will be assumed that:

$$
q X_{R}\left[\frac{r}{r+b[1-r]}\right]>1
$$

Given (19), with $\lambda>0$ small enough, we will have

$$
\hat{r}_{2}^{R}(s) X_{R}>1
$$

and we assume this holds. The implication of (20) is that a bank that experienced repayment success on a first-period $P$ loan at $t=2$ will have such a high posterior probability of success in the second period that an $R$ loan will be socially efficient given those beliefs.

Second-Period Lending Choice: Now consider the second-period lending choice for a bank whose firstperiod $P$ loan was repaid. If it makes a $P$ loan at $t=2$, its expected profit is:

$\bar{\pi}_{2}^{P}=\left\{\begin{array}{l}r_{2}^{P}(s)\left\{X_{P}-\bar{D}_{P}\left(r_{2}^{P}(s)\right)\right\} \text { of revealed at } t=1 \text { that loan success probability is exogenous } \\ \hat{r}_{2}^{P}(s)\left\{X_{P}-\bar{D}_{P}\left(\hat{r}_{2}^{P}(s)\right)\right\} \text { of revealed at } t=1 \text { that loan success probability is skill }- \text { dependent }\end{array}\right.$

where $\bar{D}_{P}$ is the promised repayment on the debt financing raised by the bank at $\mathrm{t}=2$ to finance its loan. The bank views the posterior probability at $t=2$ as either $r_{2}^{P}(s)$ or $\hat{r}_{2}^{P}(s)$, depending on the revelation at $t=1$, a so the bank's expected payoff is $r_{2}^{P}(s)\left\{X_{P}-\bar{D}\left(r_{2}^{P}(s)\right)\right\}$ or $\hat{r}_{2}^{P}(s)\left\{X_{P}-\bar{D}\left(\hat{r}_{2}^{P}(s)\right\}\right.$.

The bank's repayment obligation to debt investors should be such that the amount raised from these investors at $t=0(\$ 1)$ equals the expected payoff to them at $t=2$, i.e.

$$
\bar{D}_{P}(z)=\frac{1}{z}, z \in\left\{r_{2}^{P}(s), \hat{r}_{2}^{P}(s)\right\}
$$

I now turn to the $R$ loan. An obvious but useful result to note is the following:

Lemma 1: If the bank makes an $R$ loan at $t=2$ and it is discovered at $t=3$ that the loan repayment probability is purely exogenous, then debt investors will demand immediate repayment at $t=3$ and force the liquidation of the bank. 
The reason for this result is that the liquidation value of the $R$ loan exceeds its expected terminal value under prior beliefs. This implies that if the bank chooses to invest in the $R$ loan at $t=2$, it must promise debt investors a repayment of $\bar{D}_{R}\left(q r_{2}^{s}\right)$, which satisfies:

$$
\lambda L+[1-\lambda] q r_{2}^{s} \bar{D}_{r}\left(q r_{2}^{s}\right)=1
$$

implying that

$$
\bar{D}_{R}\left(q r_{2}^{s}\right)=\frac{1-\lambda L}{[1-\lambda] q r_{2}^{s}} .
$$

The bank's expected profit from an $R$ loan is:

$$
\bar{\pi}_{2}^{R}=[1-\lambda] q r_{2}^{s}\left\{X_{R}-\bar{D}_{R}\left(q r_{2}^{s}\right)\right\}
$$

The following result can now be proved:

Proposition 1 (Bank's Second-Period Lending): Suppose it is revealed at date $t=1$ that the loan repayment probability is purely exogenous. Then the bank will invest in a P loan in the second period, regardless of the first-period outcome. The bank will promise its debt investors a repayment at $t=4$ of $\bar{D}_{P}\left(r_{o}^{P}\right)=1 / r_{o}^{P}$, and its expected profit will be $\bar{\pi}_{2}^{P}=r_{o}^{P}\left[X_{P}-\bar{D}_{P}\left(r_{o}^{P}\right)\right]$. Suppose it is revealed at date $t=1$ that the loan repayment probability is skill-dependent. Then the bank will: (i) exit the market in the second period of its first-period loan defaults, and (ii) if its first-period loan repays, then for $\lambda \in(0,1)$ small enough $\exists r_{2}^{s}($ cut-off $)$ such that the bank prefers to make an $R$ loan at $t=2$ if $r_{2}^{s}>r_{2}^{s}(c u t-o f f)$ and a P loan otherwise. If it invests in the R loan, its repayment obligation to debt investors is $\bar{D}_{R}\left(q r_{2}^{s}\right)$ given by (24) and its expected profit is $\bar{\pi}_{2}^{R}$ given by (25).

Before getting to the intuition for the result, note that it is only in the state in which it was revealed at $t=1$ that the loan repayment probability depends on bank skill and there is repayment on the first-period loan that the bank is able to ever consider making an $R$ loan at $\mathrm{t}=2$.

If the loan repayment probability is purely exogenous, then the beliefs about second-period loan success remain the same as the prior beliefs at $t=0$, so the $P$ loan is the only viable second-period 
investment. But if the loan repayment probability depends on the bank's skill/type, then first-period failure lowers the expected second-period repayment probability so much that even a $P$ loan is not viable, whereas first-period success raises the posterior belief about the bank being talented sufficiently to ensure that the expected second-period repayment probability with an $R$ loan is high enough to make it more attractive than the $\mathrm{P}$ loan.

Since first-period loan success leads to the posterior belief about the bank being talented rising above the prior belief, and this higher posterior belief leads to higher expected second-period repayment probabilities for both $P$ and $R$ loans, one may wonder why the $R$ loan is preferred in the second period in this case. The reason is that the difference in repayment probabilities across talented and untalented banks is higher for the $R$ loan than for the $P$ loan. For the $P$ loan, this difference is $1-b$, whereas for the $R$ loan it is $q$. By (5) we know that $q>1-b$. Hence, an upward revision in the belief about the bank's skill increases the attractiveness of the $R$ loan relative to the $P$ loan. It will be assumed, henceforth, that $\lambda$ is small enough that $E_{2}^{s}>r_{2}^{s}($ cut-off $)$ following repayment of the first-period $P$ loan.

\section{B. Analysis of Outcomes at $\mathbf{t}=\mathbf{0}$.}

The following result is immediate, given our earlier analysis.

Proposition 2 (Bank's First-Period Lending): At $t=0$, all banks invest in P loans. Investors are

promised a repayment of $D_{P}\left(r_{o}^{P}\right)$ at $t=2$, where

$$
D_{P}\left(r_{o}^{P}\right)=1 / r_{o}^{P}
$$

and the bank's expected profit is

$$
\pi_{1}^{P}=r_{o}^{P}\left[X_{P}-D_{P}\left(r_{o}^{P}\right)\right]
$$

\section{Financial Crises.}

Given Propositions 1 and 2, one can now readily see how financial crises can arise.

Proposition 3 (financial crisis): There is no financial crisis in the first period. In the second period, conditional on a revelation at date $t=1$ that the loan repayment probability depends on bank skill, all 
banks that experience first-period repayment success make $R$ loans in the second period at $t=2 . A$ financial crisis occurs in the sense that all these banks fail at $t=3$ if investors learn at that time that the loan repayment probability depends on bank skill. Otherwise, there is no financial crisis and investors wait until $t=4$ to be repaid.

The sequence of events is that banks initially make prudent loans, so that, regardless of what is revealed at $t=1$, there is no crisis. Conditional on revelation at $t=1$ that bank success is skill-dependent, the banks that are successful in the first period invest in $R$ loans in the second period. ${ }^{11}$ Even if $\lambda$ is small, there is a positive probability that at $t=3$ investors will learn that the loan repayment probability in the second period is exogenous. This makes it preferable for them to demand immediate repayment at $t=3$, forcing liquidation of banks and precipitating a crisis. A key aspect of this result is that a financial crisis follows good performance by banks, a result whose dynamic implications are explored further below.

\section{The Effect of More Time Periods}

Imagine now that the previous analysis represented the first two periods of an arbitrarily long time horizon, i.e., $t=T>4$ is an arbitrarily large number. Also, instead of a single $R$ loan, there is a large set of $R$ loans, say $\left\{R_{1}, R_{2}, \ldots, R_{N}\right\}$, with $N$ arbitgrarily large. The probability distribution for loan $R_{i}$ is that a type- $\tau$ bank will be able to ensure w.p.l that it is a $\hat{G}_{i}$ loan, where $\hat{G}_{i}$ loan pays of $X_{R}^{i}$ w.p.q, and 0 w.p. 1-q, and $X_{R}^{i}>X_{R}^{j}$ if $i>j$, whereas a type- $u$ bank will ensure w.p.l that it is a $\hat{B}_{i}$ loan, where a $\hat{B}_{i}$ loan generates a payoff of $-[i-1] k$, where $k>0$ is a positive constant.

Let the liquidation value of loan $R_{i}$ be $L_{R}^{i}$, with $L_{R}^{i}<r q X_{R}^{i}-[1-r][i-1] k$, and $L_{R}^{i} \leq L_{R}^{j}$ for $i>j$. That is, riskier loans have lower liquidation values.

11 This is despite the fact that whether loan repayment probabilities are skill dependent or not in the first period is uncorrelated with that event in the second period. 
A feature of this set of $R$ loans is that the expected value of loan $R_{i}$ is $E V_{i}=r q X_{R}^{i}-[1-r][i-1] k$. Thus, $\partial E V_{i} / \partial r=q X_{R}^{i}+[i-1] k>0$, which means that the expected value of the loan increases as the belief about the bank being of type $\tau$ goes up. Moreover, $\partial^{2} E V_{i} / \partial i \partial r=q\left[\partial X_{R}^{i} / \partial i\right]+k>0$, which means that the marginal impact of an increase in the posterior belief that the bank is type $\tau$ is greater for larger values of $i$. Moreover, if we view the bank's loss given default as a measure of risk, then this loss, $[i-1] k$, is increasing in $i$, implying that loan $R_{i}$ is riskier than loan $R_{j}$ if $i>j$.

Assume now that the lowest repayment the bank can make to the creditors is zero ${ }^{12}$. Then the following result can be proved:

Proposition 4: Conditional on consecutive revelations that the loan repayment probability is skill dependent, the longer the bank experiences loan repayment success the more attractive the riskier $R_{i}$ loans become to the bank. In any period in which investors learn that the loan success probability is exogenous, there will be a financial crisis.

In this case, we see that in the first period, all banks will invest in the $P$ loan. Conditional on a revelation at $t=1$ that loan repayment probabilities are skill dependent, the banks whose first-period loans repaid will invest in $R_{1}$ loans in the second period. If there is a sufficiently long sequence (which could be as low as one period) of periods in which loans are repaid and repayment probabilities are revealed to be skill dependent (and the probability of such a sample path will be high if $\lambda$ is small), then banks will switch to $R_{2}$ loans. This will continue, so that the longer the "bull credit market run" continues the riskier will be the loans that banks invest in. Then if investors learn in any period that the loan success probability is exogenous, a crisis occurs. Once the crisis occurs, the risks taken by banks may seem shockingly "excessive" when viewed from the vantage point of those who may have ignored a lowfrequency event associated with a low $\lambda$.

\footnotetext{
12 This is a harmless assumption. The results are qualitatively unchanged if it is dropped.
} 
As long as $\lambda$ is small, the probability of occurrence of a crisis will also be low. It will also imply that when a crisis does occur, banks will find themselves stuck with riskier loans (with possibly smaller liquidation values).

\section{ANALYSIS OF THE MODEL WITH A LOAN RESALE MARKET}

While the basic model delivers the central result related to financial crises, it does not permit an examination of why asset market liquidity dries up during a crisis. This is because asset markets have no liquidity in the model. If investors withdraw funding at $t=1$ or $t=3$, the bank is forced to liquidate the loan. So in this section I introduce a loan resale market.

\section{A. Additional Structure to Accommodate Loan Resale Market}

Analyzing the loan resale market requires additional structure, which is provided below.

Liquidity Shocks and Investor Actions: W.p. $\theta \in(0,1)$ investors of a given bank experience an idiosyncratic liquidity shock at $t=1$ that creates for them an urgent demand for liquidity. We assume that these liquidity shocks are independently and identically distributed (i.i.d.) in the cross-section of banks. Investors respond to this shock by demanding immediate repayment by the bank. ${ }^{13}$

The Bank’s Response to Investor Actions: When investors demand immediate repayment, the bank has two choices. One is to repay investors by liquidating its loan prematurely and realizing a liquidation value of $L \in(0,1)$. The other is to sell its loan to another bank and pay investors from the loan sale proceeds. ${ }^{14}$ What price the loan can be sold at depends on the competitive structure of the loan resale market, which is endogenous. Potential buyers of the loan act as Bertrand competitors in this market, so the loan resale price depends on the number of banks that are willing and able to buy the loan. We

\footnotetext{
${ }^{13}$ This can be viewed as a "dark side" of (uninsured) wholesale funding, as in Huang and Ratnovski (2011). Thus, while the information about whether loan repayment probabilities are exogenous or skill dependent can be viewed as a systematic shock, this is an idiosyncratic shock.

${ }^{14}$ The difference between liquidating and selling a loan can be thought of as follows. When a bank liquidates a loan, it may either force the borrower to repay early by selling off real assets prematurely at a loss or it may transfer the loan to a non-bank lender at a heavy discount since that non-bank lender can realize only a fraction of the loan value that the bank can. When a bank sells a loan, it transfers ownership to another specialized lender, a bank. The purchasing bank can realize the full value of the loan that the selling bank could have if it had not sold it.
} 
assume that only a bank that has not suffered a withdrawal of funding by its investors and has already invested in that type of loan previously on its own, is in a position to buy another bank's loans. ${ }^{15}$ There are no capacity limits on how many loans such a bank can buy at $t=1 .{ }^{16}$ Whether the bank that suffers a liquidity shock sells its loan in the secondary market or liquidates the loan depends on the (endogenouslydetermined) loan resale price at $t=1$.

The debt contract with these investors, set at $t=0$, stipulates that the investors receive the market price of their debt if they withdraw at $t=1$, subject to the limited liability constraint governing the bank's ability to repay. Thus, investors receive the minimum of the proceeds the bank receives from the loan sale (or liquidation if the loan cannot be sold) and the expected value (determined at $t=1$ ) of the date-2 repayment amount owed to the investors. ${ }^{17}$ A bank that suffers a liquidity shock at $t=1$ can continue to exist only if it can pay investors the market price of their debt at $t=1$. Otherwise it ceases to exist. If it survives, then it has no loan in its portfolio until $t=2$, but investors revise their belief about the bank's type based on whether the loan it sold to another bank eventually repaid or defaulted at $t=2$.

The Purchasing Banks: For the banks that purchase loans from other banks at $t=1$, it is assumed that the purchasing bank pays the selling bank a price for the loan, but does not assume any of the seller's liabilities against that loan. ${ }^{18}$ The purchase price will be financed by the purchasing bank with new debt issued at $t=1$. Every purchased loan is put by the buying bank into a legally-separate (bankruptcy-remote) trust or organization set up for the purchased loan, so that the repayments on the purchased loans are unavailable to repay the investors who funded the purchasing bank at $t=0$, and these investors are also not liable for any of the defaults on the purchased loans. ${ }^{19}$ That is, investors who fund loan $i$ in a given bank

\footnotetext{
${ }^{15}$ Thus, for example, a bank that invested in a prudent loan would not be in a position to buy risky loans.

${ }^{16}$ This is not very realistic, and ideally one would like a capacity limit—say each loan buyer can buy at most one loan-but this complicates the model without adding insight.

${ }^{17}$ Conditional on the loan sale proceeds being sufficient, paying investors less than the expected value of what is owed to them (market price) would imply an "early withdrawal" penalty that would simply be reflected in the $e x$ ante pricing of debt at $t=0$, and paying them more would induce investors to demand repayment at $t=1$ even if not hit with a liquidity shock.

${ }^{18}$ Recall that the bank that sells its loan uses the proceeds to pay off its liabilities.

${ }^{19}$ So the structure is similar to that with securitization, where SPVs (Special Purpose Vehicles) are used to segregate the securitized asset from the bank's other assets. This assumption is made to eliminate unnecessary analytical complexity.
} 
are paid only from repayment on loan $i$ and do not receive any of the repayment on loan $j(\neq i)$ if loan $i$ defaults.

Expertise to Manage R Loan: The $R$ loan is a more complex asset than the $P$ loan, so it requires the bank to acquire special expertise to manage the loan. The cost of acquiring this expertise varies in the cross-section and is $C_{i} \geq 0$ for bank $i$, with $C_{i} \in[0, \bar{C}] \subset \square_{+}$.

Banks that are not Hit by Liquidity Shocks at $\mathbf{t}=1$ : If the bank is not hit by a liquidity shock at $t=1$, then investors who provided funding at $t=0$ are repaid at $t=2$ an amount equal to the face value of the debt conditional on the bank receiving repayment from the borrower. Any surplus left over is paid as a dividend to the bank's shareholders at $t=2$. The bank then makes a new loan at $t=2$ if it is able to raise financing for it. The cycle then repeats. Once again, the choice is between two mutually-exclusive assets: the prudent loan and the risky loan. At $t=3$ (as at $t=1$ ), investors receive a signal about the bank's true success probability at $t=4$, which says w.p. $\lambda$ that the success probability is exogenous. The bankspecific liquidity shock is also realized w.p. $\theta$ at $t=3$. There are then loan sales and possibly liquidations at $t=3$. A bank hit with a liquidity shock at $t=3$ essentially ceases to exist regardless of whether it liquidates or sells its loan, since it no longer has a loan on its books and $t=4$ is the terminal date. If the bank survives, it continues until $t=4$, at which time loan repayments are collected and investors are paid off if possible.

\section{B. Second-Period Analysis with a Loan Resale Market}

The previous analysis does not deal with the ability of a bank to offset the loss of liquidity on the liability side by selling assets. Being able to do this may reduce (or even eliminate) the probability of a crisis. This is examined next.

Suppose there are $N$ banks that can raise financing and operate at $\mathrm{t}=2$. To examine the effect of the loan resale market, note that there are three possible scenarios facing a bank that wishes to sell its loan at $t=3$ : (i) there are no potential buyers for the loan; (ii) the number of potential buyers for the loan is equal to one; and (iii) there are two or more potential buyers. 
In case (i), with no banks available to buy the bank's loan, it is forced to liquidate and realize a value of $L$ for the loan. In case (ii), with only one potential buyer, the buyer can act as a monopolist and pay a price equal to the seller's reservation price, which is the liquidation value, $L$. Thus, cases (i) and (ii) are identical for the bank wishing to sell the loan.

If there are two or more potential buyers (case (iii)), then Bertrand competition among them ensures that the expected return on the loan purchase for the buyer is zero and the selling bank receives the same expected value that it would have if it had retained the loan.

The probability that there are two or more potential buyers for the loan at $t=3$, given that $N$ banks made $P$ or $R$ loans at $t=2$, is 1 minus the probability that one or no bank avoided getting the liquidity shock (i.e., the probability that the liquidity shock hit all banks or all but one):

$$
\delta \equiv 1-\left\{\theta^{N-1}+\theta^{N-2}[1-\theta]\right\}
$$

Analysis when all banks make second-period P loans: Suppose every bank made a $P$ loan at $t=2$, after having been repaid on $P$ loans made at $t=0$, as before, banks that experienced defaults on first-period loans exit the market. Combining cases (i), (ii) (iii), yields the following result:

Lemma 2: With a loan resale market, if the bank invests in a $P$ loan at $t=2$, it must promise investors a repayment of $\hat{D}_{P}(z)$ to raise $\$ 1$, where:

$$
\hat{D}_{P}(z)=\frac{\{1-\theta[1-\delta] L\}}{[1-\theta+\theta \delta][z]}>1
$$

where $z=r_{2}^{p}(s)$ if it was revealed at $t=1$ that the loan repayment probability is exogenous, and $z=\hat{r}_{2}^{P}(s)$ if it was revaled at $t=1$ that the repayment probability is skill-dependent, with $r_{2}^{P}(s)$ given by (14) and $\hat{r}_{2}^{P}(s)$ by (17).

$\hat{\pi}_{2}^{P}=[1-\lambda]\left\{[1-\theta]\left\{Y_{P}+[N-1] \theta^{N-1}\left[T V_{P}-L\right]\right\}+\theta \delta Y_{P}\right\}+\lambda\left\{[1-\theta]\left\{\bar{Y}_{P}+[N-1] \theta^{N-1}\left[T \bar{V}_{P}-L\right]+\theta \delta \bar{Y}_{P}\right\}\right.$

where: 


$$
\begin{aligned}
& Y_{P}=z\left[X_{P}-\hat{D}_{P}(z)\right] \text { and } z \in\left\{r_{2}^{P}(s), \hat{r}_{2}^{P}(s)\right\} \\
& T V_{P}=z X_{P} \text { and } z \in\left\{r_{2}^{P}(s), \hat{r}_{2}^{P}(s)\right\} \\
& \bar{Y}_{P}=r_{o}^{P}\left[X_{P}-\hat{D}_{P}(z)\right] \\
& \overline{T V}_{P}=r_{o}^{P} X_{P}
\end{aligned}
$$

The expressions in Lemma 2 can be interpreted as follows. Let us begin with a discussion of how the face value of debt, $\hat{D}_{P}(z)$, in (29) is arrived at. With a loan resale market, when investors experience a liquidity shock and demand repayment at $t=3$, the bank does not necessarily have to liquidate and pay $L$ to investors. It may be able to sell the loan to another bank. If the loan resale market is competitive (the probability of which is $1-\theta+\theta \delta$ ), then the bank will receive a price that is equal to the expected value of the loan to the buyer, which is $T V_{P}$, the total market value of the loan. From this amount, investors who provided funding at $\mathrm{t}=0$ can be paid the market price of their debt, $z\left[\hat{D}_{P}(z)\right]$. But, if there is only one buyer, then this buyer will pay only $L$ (the probability of this is $\theta[1-\delta]$ ), for the loan, since this liquidation value is the seller's reservation price. Similarly, if the bank has to liquidate the loan because there are no buyers, it will receive $L$. In both cases, whether there is no buyer or only one buyer, investors will have to take a haircut and will get paid only $L$, and the bank's profit is zero. The expression in (29) results from this calculation to ensure that investors set the face value of the debt, $\hat{D}_{P}(z)$, such that its expected value at $t=0$ is $\$ 1$, the amount of initial financing provided.

Turning to the bank's expected payoff in (30), it can be seen that it consists of two parts. One part is when it experiences no liquidity shock (probability $1-\theta$ ). In this case, the bank earns an expected profit of $Y_{P}$ on its loan and it is also able to earn a profit of $T V_{P}-L$ on purchased loans if all the other banks $N-1$ suffer liquidity shocks (probability $\theta^{N-1}$ ), and this bank is able to act as a monopolist and purchase all of these loans at $L$ each (it would need to borrow $L$ for each loan, but the expected value of its promised repayment to debt investors is $L$ per loan). If $N-2$ or fewer banks suffer liquidity shocks, 
then there are two or more potential loan buyers (including this bank), so the loan resale market is perfectly competitive and the bank's expected profit from buying a loan is zero. The other part of the bank's expected payoff refers to the event when it experiences a liquidity shock (probability $\theta$ ), in which the case the bank's expected profit is $Y_{P}$ if the loan resale market is competitive (probability $\delta$ ) and zero otherwise.

Analysis when all banks make second-period $\boldsymbol{R}$ loans: Next assume that every bank made an $R$ loan at $\mathrm{t}=2$. Then we have the following result. ${ }^{20}$

Lemma 3: With a loan resale market, if the bank invests in an $R$ loan at $t=2$, it must promise investors a repayment of $\hat{D}_{R}\left(q r_{2}^{s}\right)$ to raise $\$ 1$, where:

$$
\hat{D}_{R}\left(q r_{2}^{s}\right)=\frac{1-\theta[1-\delta][1-\lambda] L-\lambda L}{r_{2}^{s} q\{1-\theta+\theta \delta\}}>1
$$

and the bank's expected payoff is:

$$
\begin{aligned}
& \hat{\pi}_{2}^{R}=\left\{[i-\lambda][1-\theta]\left[Y_{R}+[N-1] \theta^{N-1}\left[T V_{R}-L\right]\right]+\theta \delta Y_{R}\right\}-C_{i} \\
& Y_{R} \equiv r_{2}^{S} q\left[X_{R}-\hat{D}_{R}\left(q r_{2}^{S}\right)\right] \\
& T V_{R}=r_{2}^{S} q X_{R}
\end{aligned}
$$

The interpretation of the lemma is similar to that of Lemma 2. We now have another result:

Lemma 4: Conditional on revelation at date $t=1$ that the loan repayment probability depends on the bank's skill, the existence of the loan resale market: (i) increases the bank's second-period expected payoffs on both the $P$ and $R$ loans; and (ii) it increase the number of banks that can offer the $R$ loan in the second period, but does not affect the number of banks that can offer the P loan in the second period.

It is intuitive that the existence of the loan resale market increases the bank's expected profits on both types of loans. Without a loan resale market, a bank hit with a liquidity shock must liquidate its loan and collect $L$, all of which goes to the creditors, leaving nothing for the bank's shareholders. With a loan

\footnotetext{
${ }^{20}$ Note that we can use $\delta$ here as well since no one in this economy expects the information signal about the true loan value until it actually arrives. Hence, the calculation of $\delta$ does not reflect $\lambda$.
} 
resale market, there is a positive probability that the bank can sell its loan at a price sufficiently higher than $L$ to generate a positive expected profit for its shareholders even in the state in which there is a liquidity shock. In short, the existence of a secondary market makes both types of loans more liquid, enhancing their profitability to the bank.

The loan resale market does not affect the number of banks that can offer $P$, because $P$ is profitable for banks even at the prior belief $r$ and without a loan resale market. Loan $R$, however, is profitable for banks only if the posterior belief, $r_{2}^{S}$, is high enough and the cost of acquiring expertise, $C_{i}$, is low enough. Since the loan resale market increases the profitability of $R$ to the bank, the cut-off $C_{i}$ such that banks with $C_{i}$ 's below that cut-off can participate in $R$ goes up. As a consequence, the emergence of the loan resale market increases the number of banks that can offer $R$.

This is an interesting result because it shows that the loan resale market, whose primary purpose is to increase bank liquidity and thereby lower the probability of a crisis when investors are hit ex post with a liquidity shock, induces banks to invest in riskier assets ex ante. This contributes to an increase in the probability of a crisis.

This lemma also allows us to establish a result that is important for the subsequent analysis. Before establishing that result, it is useful to simplify the specification of the cost. Assume that $C_{i} \in\{0, \underline{C}, \bar{C}\}$, with $0<\underline{C}<\bar{C}$, and prior to the opening of the loan market at $t=2$, each bank randomly draws $C_{i}$ equal to $0, \quad \underline{C} \quad$ or $\quad \bar{C}$. Let $\operatorname{Pr}\left(C_{i}=0\right)=\gamma_{0} \in(0,1), \quad \operatorname{Pr}\left(C_{i}=\underline{C}\right)=\gamma_{1} \in(0,1), \quad$ and $\operatorname{Pr}\left(C_{i}=\bar{C}\right)=1-\gamma_{0}-\gamma_{1}$

Further, it will be assumed that

$$
q X_{R}-\bar{C}>X_{P}
$$

which is a stronger version of (4) with the introduction of the maximum cost, $\bar{C}$, of acquiring the skills to manage $R$. 
Some additional notation is also necessary. Let $n_{0}, n_{1}$, and $n_{2} \equiv N-n_{0}-n_{1}$ be the number of banks at $t=2$ that had success on their first-period loans and realized $C_{i}=0, C_{i}=\underline{C}$, and $C_{i}=\bar{C}$, respectively. We can now state a result that is important for the subsequent analysis.

Proposition 5 (date-2 lending choice with a loan resale market): Conditional on revelation at date $t=1$ that the loan repayment probability depends on bank skills, there exists a cut-off value of the posterior belief of making a good loan, $r_{2}^{s}$, call it $r_{2}^{s}$ (cut-off) $\in(0,1)$ such that banks that experienced repayment success on their first-period loans prefer $R$ over $P$ at $t=2$ if $r_{2}^{s}>\hat{r}_{2}^{s}$ (cut-off), and they prefer $P$ over $R$ if $r_{2}^{s}<\hat{r}_{2}^{s}($ cut-off)

Moreover, $\hat{r}_{2}^{s}$ (cut-off) is an increasing function of $C_{i}$, with a distinct cut-off for each $C_{i}$, and

(1) $\hat{r}_{2}^{s}\left(0, n_{0}\right)<\hat{r}_{2}^{s}\left(\underline{C}, n_{0}\right)<\hat{r}_{2}^{s}\left(\bar{C}, n_{0}\right)$;

(2) $\hat{r}_{2}^{s}\left(C_{i}, n_{0}\right)>\hat{r}_{2}^{s}\left(C_{i}, n_{0}+n_{1}\right)>\hat{r}_{2}^{s}\left(C_{i}, N\right)$.

Assuming $\lambda$ is sufficiently small, the expected number of successful banks at $t=2$ that will prefer $R$ over $P$ for their second-period loans is a non-decreasing function of $N$, the number of banks that are successful at $t=2$, and for values of $N$ high enough, a majority of banks prefer $R$ over $P$.

The intuition for the cut-off is that the bank's profitability in lending for both $P$ and $R$ loans increases with the posterior belief that the bank is type $\tau$, but it increases at a faster rate with the $R$ loan. It is also clear why the cut-off is increasing in $C_{i}$, since higher values of $C_{i}$ make $R$ less attractive to banks. The intuition for why the expected fraction of successful banks preferring $R$ over $P$ goes up with $N$, the number of successful banks, is as follows, and here the loan resale market plays a role. As $N$ increases, $\gamma_{0} N$, the number banks with $C_{i}=0$ goes up, and we know from the previous analysis that these banks prefer $R$, so the number of banks above the cut-off increases. The more banks opt for $R$, the larger is the loan resale market for this loan and the greater is the liquidity of this loan. This increases the expected profits of banks offering $R$, and banks with higher values of $C_{i}$ switch over from $P$ to $R$. While 
it is true that an increase in $N$ increases the potential liquidity of $P$ as well, the marginal benefit of higher liquidity in the loan resale market is higher for $R$ than for $P$.

Thus, the larger the number of banks that experience success in the first period, the higher is the expected number of banks that invest in the risky loan, i.e., the risky loan market in the second period becomes larger and more liquid as a consequence of greater success experienced by banks with the prudent asset in the first period. This result sheds light on the high liquidity in the asset markets in which banks operated prior to the crisis. This leads to the next result:

Proposition 6: Investors demand immediate repayment from a bank with a $P$ loan at $t=3$ only if they experience a liquidity shock. The bank will be liquidated only if it cannot find a buyer for its loan. Investors demand immediate repayment from a bank with an $R$ loan at $t=3$ if they experience a liquidity shock or if they receive a signal that the true success probability of $R$ is exogenous. In the former case, the bank is liquidated only if it cannot find a buyer for its loan, but in the latter case, all banks that have made $R$ loans are liquidated. The higher is the posterior belief of making a good loan, $r_{2}^{s}$, at $t=2$, the larger is the expected number of banks that are liquidated at $t=3$ due to investors receiving a signal that the true success probability of $R$ is exogenous and not skill-dependent.

For banks that have either $P$ or $R$ loans in their portfolios, when investors experience a liquidity shock, the bank is liquidated if there is no loan resale market, but there may be no liquidation with a loan resale market. Hence, ex post the likelihood of bank liquidation is diminished due to the liquidity provided by the loan resale market. Moreover, as in the case without a loan resale market, investors do not demand repayment from banks that made $P$ loans if they learn its true success probability is exogenous.

The reason why banks with $R$ loans are liquidated at $t=3$ in the event investors receive a signal that the true success probability of $R$ is exogenous is that the expected value of the $R$ project in this case is less than $L$, the liquidation value of the loan. Since all banks invested in $R$, they are all affected by this market-wide signal and are liquidated. Consequently, there is no solvent bank that is available to buy $R$ in 
the secondary market. As $r_{2}^{S}$ increases, we know from Proposition 5 that the expected number of banks opting for $R$ goes up as well. Thus, in the event that investors learn that the true probability of success of the loan is exogenous, the expected number of banks that are liquidated is higher when $r_{2}^{S}$ is higher.

\section{E. First-Period analysis}

Given (3), we know that no bank can make an $R$ loan at $t=0$. Thus, all banks invest in $P$ loans. The following result is immediate, given our preceding analysis:

Lemma 5: At $t=0$, all banks invest in $P$ loans. Investors are promised a repayment of $\hat{D}_{P}\left(r_{o}^{P}\right)$ at $\mathrm{t}=2$ in order for the bank to raise $\$ 1$ at $\mathrm{t}=0$, where

$$
\hat{D}_{P}\left(r_{o}^{P}\right)=\frac{\{1-\theta[1-\delta] L\}}{[1-\theta+\theta \delta]\left[r_{o}^{P}\right]}>1
$$

and the bank's expected payoff is:

$$
\hat{\pi}_{1}^{P}=[1-\theta]\left\{Y_{P}\left(r_{o}^{P}\right)+[N-1] \theta^{N-1}\left[T V_{P}\left(r_{o}^{P}\right)-L\right]\right\}+\theta \delta Y_{P}\left(r_{o}^{P}\right)
$$

where

$$
\begin{aligned}
& Y_{P}\left(r_{o}^{P}\right)=\left[r_{o}^{P}\right]\left[X_{P}-\hat{D}_{P}\left(r_{o}^{P}\right)\right] \\
& T V_{P}\left(r_{o}^{P}\right)=\left[r_{o}^{P}\right] X_{P}
\end{aligned}
$$

The probability that the bank will survive until the second period beginning at $t=2$ is $[1-\theta]+\theta \delta$.

The bank's survival probability is the probability there is no liquidity shock (which is $1-\theta$ ) plus the probability of the liquidity shock $(\theta)$ times the probability, $\delta$, that the loan can be sold at its expected value, $Y_{P}\left(r_{o}^{P}\right)$. If the loan can only be sold at $L$, the bank has to pay investors $L$ and it has to shut down at $t=1$. 


\section{CRISIS CYCLES, TRANSITORY VERSUS PERMANENT SHOCKS, INTERPRETATION OF THE RESULTS AND POLICY IMPLICATIONS}

This section is organized in two parts. In the first part, I discuss how the model can be extended to generate a theory of "crisis cycles". In the second part, I discuss how the differences between the theory developed here and the usual moral hazard story lead to a different set of policy prescriptions for how to reduce the likelihood of crises.

\section{A. A Theory of Crisis Cycles}

Imagine an extended version of the model in which, instead of having two periods of lending by banks, there is a larger number of periods. We can then see how the dynamics of credit markets might work in this setting. Banks will initially make prudent loans. Some banks will fail and exit the market, similar to what happens at $t=2$ in the model presented here. With probability $1-\lambda$ (approaching 1 for $\lambda$ approaching 0), the successful banks will have estimates of their ability revised upward. The larger the number of successful banks, the larger the number of banks making subsequent risky loans and the greater the liquidity of bank loans (in the resale market). Regulators, rating agencies, and others may then permit them to make risky loans, and investors will be willing to finance them. In the next period, many banks may fail and exit. But the surviving banks will have even higher posterior beliefs about their abilities and there may be new entrants as well. Even riskier bets will be made, at least by the surviving banks, and possibly by some of the new entrants who hire away some of the high-reputation managers from surviving banks. As long as sufficiently many banks continue to succeed and all agents continue to believe that loan repayment probabilities depend on bank skills, risk taking will keep increasing (see Proposition 4). Moreover, because the managers in the banks that are engaged in this risk taking will be viewed as highly talented, they will command high salaries in the periods leading up to the crisis. Then, if it is revealed in any period that the loan repayment probability is exogenous, a crisis will ensue. Liquidity of bank loans will dry up quite suddenly.

During the crisis, the majority of bank managers (those who invested in risky loans) will experience significant downward revisions in perceptions of their ability. Many will exit and be replaced 
by new managers. Investors will be unwilling to fund risky loans. Lending will be confined to prudent loans, and bank balance sheets will shrink as risky loans are shed. Politicians and regulators will fret about not being able to get banks to start lending (aggressively) again.

Over time, as banks keep making an increasing number of prudent loans, these loans will pay off and the perceptions of the abilities of the new managers will rise. While the old risky loans are largely discredited in the eyes of the investors, new types of risky loans will be introduced into the market. When perceptions of bankers' abilities are high enough, banks will begin to invest in these new risky loans and the cycle will start all over again. We will thus observe lending booms followed by crises, followed by economic and lending contractions and more conservative lending by banks, followed by lending booms and crises.

\section{B. Transitory Versus Permanent Shocks}

A key feature of the model is that the systematic " $\lambda$ shocks" - which occur if investors receive a signal that loan repayment probabilities are exogenous - are i.i.d. across different time periods. So in a given period, if the bank has made a risky loan and investors come to learn that the loan repayment probability is exogenous, they refuse to roll over their funding and the bank liquidates. If enough banks have made risky loans, there is a crisis as all these banks are liquidated.

Because the $\lambda$ shocks in the model are i.i.d. across different periods, if a bank that was liquidated could be revived in the next period, it would start that period with the same high posterior beliefs about its skill that existed prior to the crisis. This belief would receive a weight of $1-\lambda$ for the period and the belief that the loan repayment probability is exogenous and hence equal to the prior belief would receive a weight of $\lambda$. The liquidation that occurred in the previous period would not affect the expected loan repayment probability calculation in this period. The bank would thus be able to rise from the ashes and resume risky lending.

The reason why this does not happen in the model is that a bank ceases to exist once it is liquidated. However, this raises two possibilities. One is that there should be some way to redeploy the 
human capital embedded in the high posterior beliefs about the bank's type. This could be done by having a solvent bank hire the manager to run its risky loan business. The other possibility is for the government to step in and bail out the banks hit with the $\lambda$ shock by paying off creditors, and keeping these banks alive to make risky loans again in the next period. In other words, the transitory nature of the $\lambda$ shock opens up possibilities to avoid cessation of risky lending in subsequent periods even after investors refuse to roll over funding of banks in a given period.

To see how risky lending could cease for a long time following a crisis precipitated by the $\lambda$ shock, suppose the shock could be either transitory (as in the present model) or permanent. That is, w.p. $\lambda_{1} \in(0,1)$ the shock is transitory and these shocks are i.i.d. across different time periods, and $w \cdot p \cdot \lambda_{2}(0,1)$ the shock is permanent in the sense that investors believe that the loan repayment probabilities in this period and all future periods will be exogenous. While investors can tell whether the shock is transitory or permanent, banks and the government cannot. That is, one could think of these two states as referring to different "states of the mind" of investors. ${ }^{21}$ The probability that the loan repayment probability in any period is skill dependent is $1-\lambda_{1}-\lambda_{2}$, unless investors believe that the loan repayment probabilities are permanently exogenous. The following result can now be proved.

Proposition 7: With an arbitrarily large number of time periods, if investors receive a signal in any time period that the loan repayment probabilities are exogenous in a transitory sense, then banks that have made $R$ loans in that period are liquidated. However, if these banks are revived in the next period, they could resume making the same risky loans as in the period in which they were liquidated. If investors receive a signal in any time period that the loan repayment probabilities are permanently exogenous, then the banks that have made $R$ loans are liquidated, and investors will not finance any banks that wish to make R loans in subsequent periods.

\footnotetext{
${ }^{21}$ Whether investors believe that the shock is temporary or permanent will depend on the nature of the shock. For example, the high default rates on Alt A and incomplete-documentation subprime mortgages may cause investors to believe that this is a permanent shock that indicates that the loan repayment probabilities on these mortgages are exogenous and high.
} 
We see then that a small modification of the model leads banks to possibly retrench permanently from making risky loans after a financial crisis in which banks are liquidated. This will happen even if the government steps in to bail out banks threatened with liquidation.

\section{Contrasting the Theory with a Standard Moral-Hazard Story: Policy Implications, and}

\section{Empirical Evidence}

This subsection teases out three implications of the model that enable one to sharply distinguish the theory developed here from the usual moral-hazard story. The common thread that runs through these implications is that the theory developed here explains precisely why banks, regulators, investors and credit-rating agencies would all be simultaneously sanguine about the consequences of high risk-taking by banks prior to the onset of a financial crisis, even in the absence of any incentive conflicts. This sharply differentiates the theory from the moral-hazard explanation which relies on an assumed acrossthe-board spike in incentive misalignment prior to a crisis, something that is hard to rationalize. Moreover, it significantly alters one's view of the kinds of regulatory interventions needed to reduce the likelihood of a financial crisis.

Financial crises arise in this model due to (rational) learning. A string of good outcomes elevates perceptions of banking skills and this skill inference entices banks to take increasing (tail) risks that promise higher and higher payoffs conditional on success. Moreover, because perceived banking skills in managing risks are high during such periods both within and outside banks, bank managers will be highly compensated, especially in institutions that are growing their book of business in these risky activities. But regulatory initiatives to limit executive pay in banking, such as those witnessed in the U.S. and elsewhere after the subprime crisis, will fail to provide an amelioration, because they will not change skill perceptions. And given elevated skill assessments, risk managers within banks — who may advocate putting the brakes on risk taking — will tend to be marginalized.

Note that it is not just the banks that elevate their skill perceptions; it is also the investors who fund banks. This means that investors will be willing to lend money to banks at relatively low risk premia even if banks choose to operate with very low capital levels. After all, who needs capital when 
assessed risk is low? Thus, if there is even a tiny perceived advantage associated with debt over equitysay due to taxes or a preference for reporting high ROE—banks will operate with relatively low capital levels. $^{22}$ Thus, one clear implication of this theory is:

Implication 1: Crises will be cyclical phenomena and are (almost unavoidably) highly likely to occur following a long period of relatively high banking profits, regardless of executive compensation and the distorting effects of government safety nets. Obviously, misaligned incentives due to compensation or safety nets will strengthen risk-taking incentives and make crises more likely, but this incentive misalignment is not necessary for generating financial crises.

However, if we were to view this world with the assumption that crises are primarily generated by misaligned incentives, we would infer that banks invested in $R$ at $t=2$, even though they knew that $R$ was socially inefficient, because of de facto and/or de jure government safety nets and compensation packages that rewarded bank managers for taking excessive tail risks at the expense of the taxpayers. In other words, the actions of banks and investors that are truly being driven by experience-based learning would be misinterpreted as moral hazard subsequent to the observation of a crisis (that would reveal ex post that the risk-taking was inefficient).

While numerous authors have focused on incentive problems as a cause of the crisis (e.g., Barth, Caprio and Levine (forthcoming), and Biais, Rochet and Woolley (2009)), the incentive-conflict viewpoint is perhaps best exemplified in the following quote:

"But this is not a crisis caused by the failure of complex financial instruments. This is a crisis caused by the failure of leaders on Wall Street.

The Heads of firms like Bear Stearns, Lehman Brothers, AIG, Countrywide Financial and Washington Mutual all too often sacrificed their firms' futures in order to maximize short-term gains. This meant under-pricing of risk in exchange for immediate fees and taking on inordinate levels of debt to invest in complex, highly uncertain instruments."

\section{Bill George in "Wall Street's Crisis of Leadership," Bloomberg BusinessWeek, October 3, 2008}

\footnotetext{
${ }^{22}$ As we pointed out in the Introduction, these developments are ubiquitous during pre-crisis periods.
} 
The contrast between the crisis explanation provided in this paper and the one above could not be more stark. While the explanation in this paper suggests that tinkering with fee structures, executive compensation packages and even the regulatory safety net will not stop future crises from occurring, the moral-hazard explanation suggests that reforming executive compensation and fixing the safety net problems will provide the necessary amelioration. In turn, the moral-hazard explanation prescribes more stringent and intrusive regulation of the form embodied in the recently-passed Dodd-Frank Act. Much of this regulation calls for increased oversight of bank investments and more sophisticated regulatory mechanisms to deal with institutions viewed as "systemically important."

However, if the theory presented here has merit, then these regulatory interventions may prove ineffective. Because these moral-hazard-based intervention proposals rely on regulators being aware of imprudent risk-taking when it is occurring (and hopefully before financial crises occur) and therefore taking steps to cope, there is an implicit assertion that regulators are not governed by the same experience-based beliefs that govern all the other agents in the economy. Thus, if regulators do not intervene and stop banks from taking excessive risks, then the conclusion is that it must be because incentive conflicts keep regulators from faithfully serving taxpayer interest. If this were true, then very heavy-handed regulation, combined with contractual approaches to aligning the interests of regulators with taxpayers, might be socially efficient. But, if regulators are making the same (rational) inferences as everybody else, including banks, capital-market investors and rating agencies, then such an approach is unlikely to prevent future crises. ${ }^{23}$ This leads to the next two implications of the learning-based theory:

Implication 2: Even if regulators exhibit no agency problems vis-à-vis taxpayers they will be less vigilant when banks are doing well, and unlikely to prevent investments in highly-risky assets, simply because they will believe, like everyone else, that banks are skilled enough to manage the risks.

\footnotetext{
${ }^{23}$ One might argue that regulators are above distortions caused by self interest that affect banks and rating agencies, and can thus prevent crises through more effective monitoring. This, however, is debatable. See Boot and Thakor (1993), and Kane (1990). The empirical evidence in Berger and Bouwman (2011) indicates that capital does increase a bank's probability of surviving a crisis. Thus, countercyclical capital requirements may not only reduce the ex ante probability of a crisis, but may also reduce the incidence of bank failures during a crisis.
} 
Implication 3: Regulators should attempt, on an ex ante basis, to put in place mechanisms that make risk-taking more expensive for the bank's shareholders when the bank is doing well, rather than contemplating ways to prevent excessive risk-taking through direct regulatory intervention in real time or relying heavily on ex post crisis resolution mechanisms. One simple mechanism for doing this is higher (equity) capital requirements that are countercyclical.

Since in my model the probability of success of the risky loan, $R$, is always less than the probability of success of the prudent loan, $P$, higher capital requirements make $R$ less attractive than $P$ for the bank's shareholders. By raising the capital requirement when banks are doing well—and the longer the industry has done well, the higher the requirement should be-risk-taking is made more expensive precisely when it is more attractive for banks. ${ }^{24}$

In the extended model, there are two kinds of shocks - an idiosyncratic liquidity shock (" $\theta$ shock") and a systematic shock that may cause investors to believe that the loan repayment probability is exogenous (" $\lambda$ shock"). In most cases, the i.i.d. nature of the $\theta$ shock will leave the economy with banks that are able to purchase loans sold by banks that are hit by the $\theta$ shock. That is, a liquid loan sale market will prevent a crisis. And even if there are capacity constraints on banks that prevent them from purchasing all the loans available, a crisis can be averted simply by the central bank standing ready to infuse liquidity into the system, say by lowering the cost of and increasing access to the discount window. In the case of a $\lambda$ shock, this will not work as the loan sale market will dry up completely. To prevent a crisis, the central bank will have to purchase enough of the $R$ loans of banks or take sufficiently large equity positions in these banks in exchange for cash to enable them to pay off their creditors. But, as Proposition 7 shows, the effectiveness of such intervention in reviving risky lending by banks will depend on the nature of the shock.

Implication 4: In the event that banks suffer large-scale interim withdrawals by their debt investors, regulators can avert a crisis ex post by giving banks increased access to liquidity if the loan

\footnotetext{
${ }^{24}$ This argument does not rely on equity capital being more costly than debt financing. It is simply based on the idea that a bank knows that a riskier investment increases the odds of losing its capital in the event of default, as in monitoring model of Holmstrom and Tirole (1997) and the sorting model of Chan, Greenbaum and Thakor (1992).
} 
sale market is functioning well, and by asset purchases or equity infusions if the loan sale market has dried up. However, in some cases, when the loan sale market has dried up (in response to a permanent systematic shock), the averting of bank liquidations by regulatory intervention will be unsuccessful in reviving risky lending by banks.

In a nutshell, the analysis here provides a straightforward way to understand numerous stylized facts related to crises, such as the cyclical occurrence of crises and booms, as well as low capital levels in banks, the apparent "marginalization" of risk managers in banks, high compensation for bank CEOs, and high pre-crisis liquidity in asset markets as well as seemingly lax regulatory (and credit-rating-agencies) monitoring of banks prior to crises. Moreover, in sharp contrast to the misaligned-incentives explanation for financial crises, the theory developed here explains why banks, regulators and rating agencies all seem to simultaneously "underestimate" risk and why market participants do not adjust contracts to correct the apparent misalignment or increase yield spreads immediately prior to the crisis in anticipation of the impending consequences of such behavior. This theory suggests that many of the regulatory initiatives that emerged in response to the recent financial crisis may not succeed in preventing future crises. These initiatives include restrictions on executive compensation in banking, pricing safety nets like deposit insurance more accurately and making the pricing risk-sensitive, putting restrictions on regulatory forbearance (e.g. of the sort put in place after the FDICA in 1991), aligning the incentives of regulators more closely with those of taxpayers, engaging in more active monitoring of systemically important financial institutions (SIFSs), etc.

What does the empirical evidence suggest about whether it is moral hazard or learning-based beliefs that drove bank behavior? Recent evidence that appears to argue in favor of the explanation provided here appears in Fahlenbrach and Stulz (2011). They uncover two key stylized facts in their empirical analysis. One is that executive compensation was only a small portion of the wealth of bank CEOs prior to and during this crisis. The major portion was related to their holding of their own banks' stock. The other is that before the crisis began, these CEOs did not reduce their holdings in their own banks, something that they would have done if the misaligned-incentives (with deliberate pursuit of tail 
risk) argument held sway. It appears then that bankers were just as surprised by the crisis as others were, consistent with the analysis in this paper (with the assumption of a very small $\lambda$ ).

\section{Why the Economy Falls to Pieces Following Credit Crises}

The preceding analysis can also be used to understand why recessions seem to follow major financial crises, such as the financial crisis of 1929 leading to The Great Depression, and the subprime crisis leading to the recession we witnessed recently. The essence of the explanation is that a crisis may lower banker' beliefs about their own skills, and if this downward revision is sufficiently large, bankers will appear to become excessively conservative in lending, possibly causing all lending to dry up. To see this, consider a modified version of the model.

A Modified Model: The focus of the modified model is on what happens after a majority of banks succeed at $t=2$ and invest in $R$ loans, and then a crisis occurs at $t=3$. In the base model, there is no analysis of post-crisis events at $t=3$. In order to examine post-crisis events, suppose that only the bank's debt investors privately learn at $t=3$ whether the loan repayment probability is exogenous (w.p. $\lambda$ ) or skill dependent $(w . p .1-\lambda)$. In the event that they learn that the probability is skill-dependent, they also come to observe the bank's type: whether it is type $\tau$ or type $u$. As in the previous analysis, let us focus on banks that made $P$ loans in the first period that repaid, so that these banks have made $R$ loans in the second period.

How a Crisis Arises: The situation of interest is one in which there is a financial crisis. This occurs when investors withdraw funding at $t=3$ after having learned: (i) that the true success probability of the $R$ project is skill-independent and equal to $r q$ (which has a probability of $\lambda$ ); or (ii) that the true success probability is skill-dependent and that the majority of banks are type- $u$. While investors withdraw funding, in case (i), banks could return to the market with $P$ loans and obtain funding, since investors would assign a success probability of $r+b[1-r]$ to these loans. 
What Banks See: It is assumed that only investors observe whether loan repayment probabilities are exogenous or skill-dependent, and in the latter case the bank's type. Banks cannot observe this, but can observe the decision of investors to renew or terminate funding.

Analysis of Modified Model: The question is: what will be the posterior beliefs of banks about their own type after the crisis has occurred? If banks could observe that investors have withdrawn funding because they believe the $R$ loan is too risky, bankers would not lower their assessments of their own skills and may be willing to invest in $P$ loans and investors would be willing to fund them. But banks do not know what investors know. All banks can observe is the crisis at $t=3$. This makes it possible that banks may erroneously lower their probability assessments of their own abilities (case (ii)) even when the crisis was triggered by investors lowering their belief about the success probability of the $R$ loan (case (i)). The posterior probability a bank will assign to the event that it is type- $\tau$ after experiencing withdrawl of its funding at $t=3$ is (referring to "funding withdrawal" as "f.w."):

$$
\begin{aligned}
& \operatorname{Pr}(\tau \mid f . w . \text { at } t=3)=\frac{\operatorname{Pr}(f \cdot w \cdot \mid \tau) \operatorname{Pr}(\tau)}{\{\operatorname{Pr}(f . w \cdot \mid \tau) \operatorname{Pr}(\tau)+\operatorname{Pr}(f . w \cdot \mid u) \operatorname{Pr}(u)+\operatorname{Pr}(f . w . \mid \text { success probability exogenous }) \lambda\}}=0 \\
& \operatorname{Pr}(u \mid f . w . \text { at } t=3)=\frac{[1-\lambda]\left[1-r_{2}^{s}\right]}{\left\{[1-\lambda]\left[1-r_{2}^{s}\right]+\lambda\right\}}
\end{aligned}
$$

Thus, after having observed funding withdrawal at $t=3$, the bank will have the posterior belief that the probability of loan repayment on a $P$ loan it can make at $t=4$ will be:

$$
\lambda[r+[1-r] b]+[1-\lambda] b
$$

since it assigns a zero proability to being of type $\tau$. If $\lambda$ is small, the above posterior will be close to $b$. Assume now that the bank must incur a cost (possibly arbitrarily small) $\Psi>0$ of investing in a $P$ loan. Thus, we have:

Proposition 8: There exists an $\lambda \in(0,1)$ small enough such that no bank that suffers a withdrawal of funding at $t=3$ and fails during a crisis will wish to invest in any loan at $t=4$ even though investors are willing to fund P loans at that time. 
The intuition is as follows. The expression in (47) is decreasing in $\lambda$, so for $\lambda$ low enough, the bank believes that it is relatively highly likely that investors received a signal that indicated that the bank was type- $u$. This makes even a $P$ loan unattractive to the bank if there is even a miniscule cost of engaging in such lending.

Since banks do not lend, this economy falls to pieces. This continues even when the financing friction that investors will not fund banks has disappeared. The reason is not a lack of availability of funds. Rather, it is the banker's lack of confidence in his own ability to make profitable loans.

\section{CONCLUSION}

This paper has proposed a theory of financial crises based on learning that leads to revisions in inferences of banking skills. In such a setting, a sufficiently long sequence of favorable outcomes for banks leads all agents - banks themselves, their investors, rating agencies, and regulators - to assign relatively high probabilities to the abilities of banks to manage their own risks. This provides banks with access to lowcost funding. Consequently, if it is revealed in the future that outcomes are skill-independent and purely exogenous, a crisis occurs as debt investors withdraw their funding from banks and the loan sale market dries up.

This theory of financial crises can explain a substantial pre-crisis build-up of liquidity, and then a sudden collapse of the system, with a rapid drying up of liquidity. The theory developed here also predicts that such financial crises will be cyclical. That is, the framework developed here explains "crisis cycles". Moreover, the analysis suggests that regulations enacted in response to crises that are intended to cope with moral hazards of various sorts may be ineffective in diminishing the likelihood of future crises.

An implication of the analysis is that as banks experience increasing success, they will keep lower amounts of liquid (cash asset) reserves, as they perceive lower probabilities of future crises. This then becomes another factor that adds to the severity of the crisis when it occurs. ${ }^{25}$

The analysis in this paper also sheds light on why the real economy falls to pieces even after the financial-market frictions that precipitated the crisis have subsided. The reason is that the crisis is

\footnotetext{
${ }^{25}$ I am grateful to Elena Carletti for this observation.
} 
accompanied by a downward revision in ability perceptions within banks, so banks become "gun shy" and cut back on investments even though investors are willing to resume funding banks.

The only learning that occurs in this model is about the bank's skill/type. One could imagine that there is also learning about $\lambda$ itself, i.e., there is uncertainty about the magnitude of $\lambda$, in addition to uncertainty about bank skill. Then an increasing sequence of observations that loan repayment probabilities are skill-dependent will lead to decreasing posterior beliefs that these probabilities are exogenous. This will reinforce the key effects modeled in this paper. 
FIGURE 1. SEQUENCE OF EVENTS

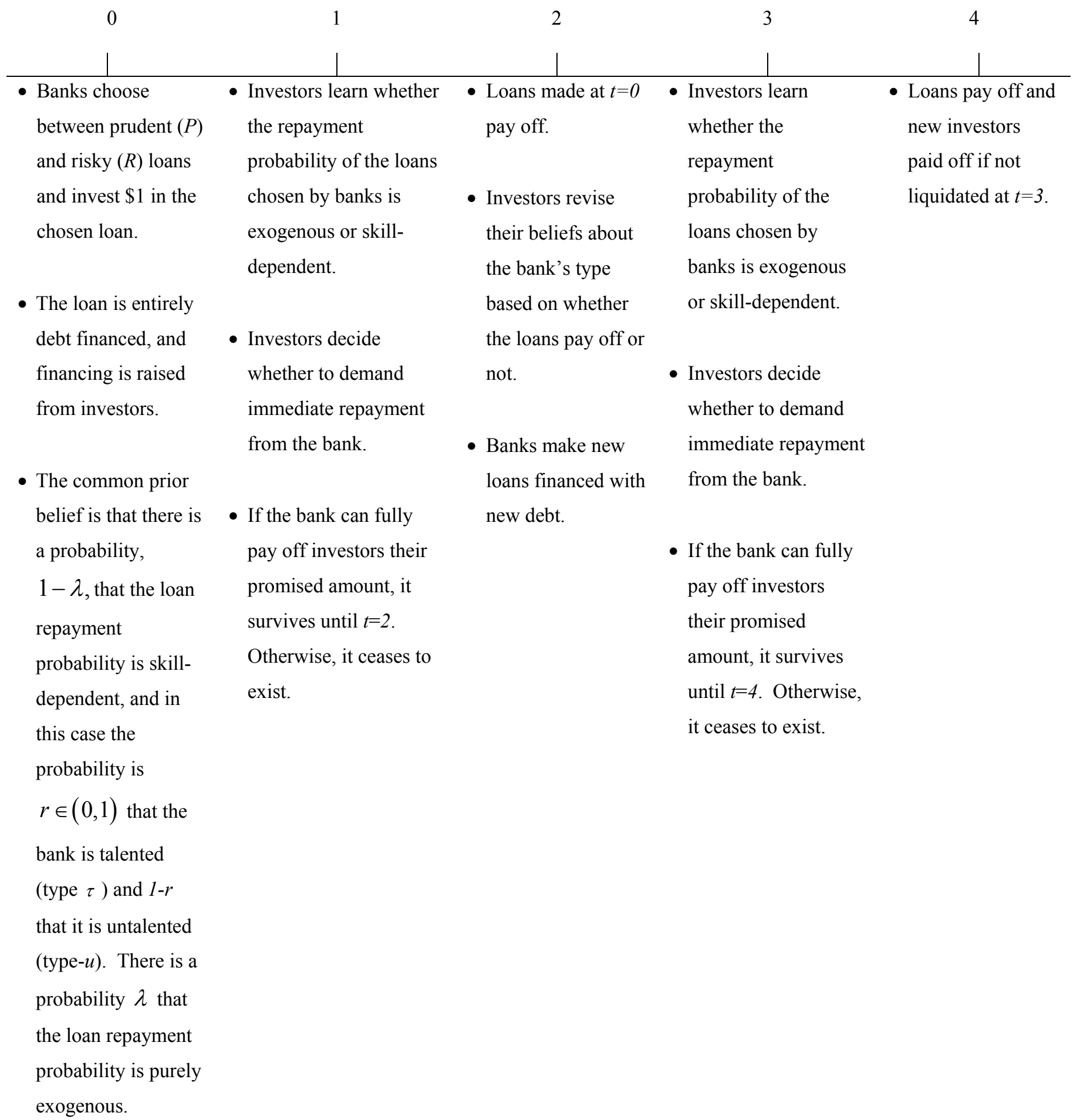




\section{APPENDIX}

\section{Proof of Lemma 1:}

If the loan repayment probability is exogenous, then this probability is $r_{o}^{R} X_{R}<1$. Thus, investors withdraw funding.

\section{Proof of Proposition 1:}

If it is revealed at $t=1$ that the loan repayment probability is exogenous, then at $t=2$ the posterior belief about the loan repayment probability becomes $r_{o}^{P}$, so the expected loan repayment probability for the second-period $R$ loan is: $\lambda r_{o}^{R}+[1-\lambda] r_{o}^{R}=r q$. Investing in the $R$ loan in the second period is therefore precluded since $r q x_{R}<1$.

Since the expected repayment probability of the second-period $P$ loan is $\lambda r_{o}^{P}+[1-\lambda] r_{o}^{P}=r+[1-r] b$ and $\{r+[1-r] b\} x_{P}>1$, the $P$ loan is chosen for the second period. $\bar{D}_{P}\left(r_{o}^{P}\right)=1 / r_{o}^{P}$ follows from the break-even condition of investors, and given this $\bar{D}_{P}$, the expression for $\bar{\pi}_{2}^{P}$ is obvious.

Now if it is revealed at $t=1$ that the loan repayment probability is skill-dependent, then default on the firstperiod loan leads to expected second-period repayment probabilities of $\hat{r}_{2}^{P}(f)$ (given by (11)) and $\hat{r}_{2}^{R}(f)$ (given by (12)) on the $P$ and $R$ loans respectively. Given (13), it follows that second-period financing can be raised for neither the $P$ nor the $R$ loan. The bank thus exits the market. If the first-period loan repays, then the bank's expected profit on the second-period loan is (see (21)):

$\bar{\pi}_{2}^{P}=\hat{r}_{2}^{P}(s)\left\{X_{P}-\bar{D}_{P}\left(\hat{r}_{2}^{P}(s)\right)\right\}$ with a $P$ loan, where $\hat{r}_{2}^{P}(s)$ is given by (17). Substituting for $\hat{r}_{2}^{P}(s)$, using (22) and simplifying yields:

$$
\bar{\pi}_{2}^{P}=\hat{r}_{2}^{P}(s) X_{P}-1
$$

Similarly, using an (24) and (25), the bank's second-period expected profit with an $R$ loan is:

$$
\bar{\pi}_{2}^{R}=[1-\lambda] q r_{2}^{s} X_{R}+\lambda L-1
$$

The rest of the proof requires comparing (A-1) and (A-2). At $r_{2}^{s}=r$, it is clear that $\bar{\pi}_{2}^{P}>\bar{\pi}_{2}^{R}$. To see this, note that the bank cannot raise financing for $R$ if the posterior belief is that the probability of the bank being of type $\tau$ is $r$. Thus, $\bar{\pi}_{2}^{R}=0$ at $r_{2}^{s}=r$. However, given (2), it is clear that $\bar{\pi}_{2}^{P}>0$ at $r_{2}^{s}=r$. 


$$
\begin{aligned}
& \text { Now, consider } r_{2}^{s}=1 \text {. Note that } \\
& \bar{\pi}_{2}^{P}=\lambda[r+[1-r] b] X_{P}+[1-\lambda] X_{P}-1 \\
& \bar{\pi}_{2}^{R}=[1-\lambda] q X_{R}+\lambda L-1
\end{aligned}
$$

Given (4) and (5), (A-3) and (A-4) show that $\bar{\pi}_{2}^{R}>\bar{\pi}_{2}^{P}$ at $r_{2}^{s}=1$ for $\lambda>0$ small enough. Since $\bar{\pi}_{2}^{P}$ and $\bar{\pi}_{2}^{R}$ are continuous functions of $r_{2}^{s}$, with $\bar{\pi}_{2}^{P}>\bar{\pi}_{2}^{R}$ at $r_{2}^{s}=r$ and $\pi_{2}^{R}>\pi_{2}^{P}$ at $r_{2}^{s}=1$, it follows that the two functions intersect at least once in $[r, 1]$. It will now be shown that they intersect only once. Now, for $r_{2}^{s} \in(r, 1)$, using (A-1) and (A-2), we have:

$$
\begin{aligned}
& \partial \bar{\pi}_{2}^{P} / \partial r_{2}^{s}=[1-\lambda][1-b] X_{P}>0 \\
& \partial \bar{\pi}_{2}^{R} / \partial r_{2}^{s}=[1-\lambda] q X_{R}>0 .
\end{aligned}
$$

Given (4), it follows that $\partial \bar{\pi}_{2}^{R} / \partial r_{2}^{s}>\partial \bar{\pi}_{2}^{P} / \partial r_{2}^{s}$. Thus, $\bar{\pi}_{2}^{P}$ and $\bar{\pi}_{2}^{R}$ will intersect only once for $r_{2}^{s} \in[r, 1]$. Thus, since $\bar{\pi}_{2}^{R}>\bar{\pi}_{2}^{P}$ at $r_{2}^{s}=1$ and $\bar{\pi}_{2}^{P}>\bar{\pi}_{2}^{R}$ at $r_{2}^{s}=r$, and $\bar{\pi}_{2}^{P}$ and $\bar{\pi}_{2}^{R}$ are strictly increasing in $r_{2}^{s}$, with $\bar{\pi}_{2}^{R}$ having a steeper slope, we see that $\exists$ a unique $r_{2}^{s}$ (cut-off) $\in(r, 1)$ such that $\bar{\pi}_{2}^{R}=\bar{\pi}_{2}^{P}$ at $r_{2}^{s}=r_{2}^{s}$ (cut-off) and $\bar{\pi}_{2}^{R}>\bar{\pi}_{2}^{P} \forall r_{2}^{s}>r_{2}^{s}$ (cut-off) and $\bar{\pi}_{2}^{R}<\bar{\pi}_{2}^{P} \forall r_{2}^{s}<r_{2}^{s}$ (cut-off).

\section{Proof of Proposition 2:}

The proof is obvious given the earlier arguments.

\section{Proof of Proposition 3:}

Since all banks $P$ loans in the first period, even if it is revealed that loan repayment probabilities are exogenous, the loans continue to be viewed as profitable, so investors never withdraw funding at $t=1$. Now, if it is revealed that loan repayment probabilities are skill-dependent and banks experience first-period success, then it follows from Proposition 1 (given that $r_{2}^{s}>r_{2}^{s}(c u t-o f f)$ ) that the bank prefers an $R$ loan to a $P$ loan in the second period. So all banks experiencing first-period success invest in $R$ loans. Clearly, if it is revealed at $t=3$ that the loan repayment probability is exogenous, investors withdraw funding and a crisis ensues.

\section{Proof of Proposition 4:}

The difference in expected payoffs between a riskier and less risky loan is 
$\Delta \equiv r q\left[X_{R}^{i}-X_{R}^{j}\right]-[1-r] k[i-j]$ for $i>j$, and

$\partial \Delta / \partial r=q\left[X_{R}^{i}-X_{R}^{j}\right]+k[i-j]>0$,

so as the posterior belief that the bank is type $\tau$ increases, the riskier loan has a higher expected value relative to a less risky loan and looks more attractive to the bank.

\section{Proof of Lemma 2:}

If investors are promised a repayment of $\hat{D}_{P}(z)$, the debt pricing condition is:

$$
[1-\theta+\theta \delta] z \hat{D}_{P}(z)+\theta[1-\delta] L=1
$$

where $\mathrm{z}$ is the loan repayment probability and $\delta$ (given by (28)) is the probability that there are two or more buyers for the bank's loans. Now (29) follows from (A-7). The bank's expected payoff in (30) follows from the discussion in the text following the statement of the lemma.

\section{Proof of Lemma 3:}

The proof follows the same steps as the proof of Lemma 2.

\section{Proof of Lemma 4:}

Use (35) and (37) to write (36) as

$\hat{\pi}_{2}^{R}=[1-\lambda]\left\{r_{2}^{s} q[1-\theta+\theta \delta] X_{R}+\theta[1-\delta][1-\lambda] L+\lambda L-1+[N-1] \theta^{N-1}\left[T V_{R}-L\right]\right\}-C_{i}$

If there is no loan resale market, then $\delta=0$ and the $[N-1] \theta^{N-1}\left[T V_{R}-L\right]$ terms drops out. Note that $\partial \hat{\pi}_{2}^{R} / \partial \delta=[1-\lambda] \theta\left\{r_{2}^{s} q X_{R}-L\right\}>0$

Thus, the loan resale market leads to a higher expected profit for the bank than when there is no loan resale market. A similar result can be established for the bank's profit with the $R$ loan.

The fact that the loan resale market does not increase the number of banks making the $P$ loan follows from the fact that the $P$ loan is profitable for all banks, even without the loan resale market, i.e., $\hat{\pi}_{2}^{P}>0$. As for the $R$ loan, $\hat{\pi}_{2}^{R} \geq 0$ requires that:

$$
[1-\lambda][1-\theta]\left\{Y_{R}+[N-1] \theta^{N-1}\left[T V_{R}-L\right]\right\}+\theta \delta Y_{R} \geq C_{i}
$$


Let $C_{i}^{0}$ be the cut-off value of $C_{i}$ at which (A-8) holds as an equality. Similarly, the condition $\hat{\pi}_{2}^{R} \geq 0$ requires that:

$$
[1-\lambda][1-\theta] r_{2}^{s} q\left[X_{R}-\hat{D}_{R}\left(q r_{2}^{s}\right)\right] \geq C_{i}
$$

Let $C_{i}^{*}$ be the cut-off value of $C_{i}$ at which (A-9) holds as an equality. Then, it is clear that $C_{i}^{0}<C_{i}^{*}$. Thus, the loan resale market increases the number of banks choosing the $R$ loan.

\section{Proof of Proposition 5:}

Part of the proof is similar to that for Proposition 1. Using arguments similar to those used in the proof of that Proposition, it can be shown that $\hat{\pi}_{2}^{P}$ and $\hat{\pi}_{2}^{R}$ are continuously increasing in $r_{2}^{s}$ with $\hat{\pi}_{2}^{P}>\hat{\pi}_{2}^{R}$ at $r_{2}^{s}=r$ and $\hat{\pi}_{2}^{R}>\hat{\pi}_{2}^{R}$ at $r_{2}^{s}=1$. From this it follows that $\exists$ a unique $\hat{r}_{2}^{s}$ (cut-off) $\in(r, 1)$ such that $P$ is strictly preferred if $r<\hat{r}_{2}^{s}$ (cut-off) and $R$ is strictly preferred if $r>\hat{r}_{2}^{s}$ (cut-off).

The fact that $\hat{r}_{2}^{s}$ (cut-off) is an increasing function of $C_{i}$ follows from the observation that $\hat{\pi}_{2}^{P}$ is decreasing in $C_{i}$. Moreover, the cost realization for a particular bank affects its cut-off since the cut-off depends on $C_{i}$. Since the cut-off is increasing in $C_{i}$, it follows that $r_{2}^{s}\left(0, n_{0}\right)<\hat{r}_{2}^{s}\left(\underline{C}, n_{0}\right)<\hat{r}_{2}^{s}\left(\bar{C}, n_{0}\right)$ given that $0<\underline{C}<\bar{C}$.

To show that, holding $C_{i}$ fixed, the cut-off $\hat{r}_{2}^{s}$ decreases as the number of successful banks with that cost realization increases, we need to show that the expected fraction of successful banks at $t=2$ that will prefer $R$ over $P$ is non-decreasing in $N$, the number of successful banks at $t=2$. For this, we need to show that $\frac{\partial \hat{\pi}_{2}^{R}}{\partial \hat{N}} \geq \frac{\partial \pi_{2}^{P}}{\partial N}$, with strict inequality for $N$ large enough. Note first that (30) can be simplified and written as:

$$
\begin{aligned}
\hat{\pi}_{2}^{P}= & {[1-\lambda]\left\{[1-\theta+\theta \delta] \hat{r}_{2}^{P}(s) X_{P}+\theta[1-\delta] L-1\right\}+\lambda\left\{[1-\theta+\theta \delta] r_{o}^{P} X_{P}-\left[r_{o}^{P} / \hat{r}_{2}^{P}(s)\right][1-\theta[1-\delta] L]\right\} } \\
& +[1-\theta][N-1] \theta^{N-1}\left\{\lambda \overline{T V}_{P}+[1-\lambda] T V_{P}-L\right\}
\end{aligned}
$$

Thus,

$$
\begin{gathered}
\partial \bar{\pi}_{2}^{P} / \partial N=\left\{\theta[1-\lambda]\left[\hat{r}_{2}^{P}(s) X_{P}-L\right]+\lambda \theta r_{o}^{P}\left[\hat{r}_{o}^{P}(s)\right]^{-1}\left[\hat{r}_{2}^{P}(s) X_{P}-L\right]\right\}\left[\frac{\partial \delta}{\partial N}\right] \\
+[1-\theta]\left\{\lambda T \bar{V}_{P}+[1-\lambda] T V_{P}-L\right\} \frac{\partial\left\{[N-1] \theta^{N-1}\right\}}{\partial N}
\end{gathered}
$$


Note that $\frac{\partial\left\{[N-1] \theta^{N-1}\right\}}{\partial N}=\theta^{N-1}+[N-1\} \ln (\theta) \theta^{N-1}, \quad \lim _{N \rightarrow \infty} \theta^{N-1}\{1+[N-1] \ln (\theta)\}=0$ since $\theta<1$, and $\partial \delta / \partial N>0(\operatorname{see}(28))$

Similarly,

$\partial \hat{\pi}_{2}^{R} / \partial N=[1-\lambda]\left\{\theta\left[r_{2}^{s} q X_{R}-[1-\lambda] L\left[\frac{\partial \delta}{\partial N}\right]+\theta^{N-1}\{1+[N-1] \ln (\theta)\}\left[T V_{R}-L\right]\right\}\right.$

Comparing (A-11) and (A-12), we see that for $\lambda$ sufficiently small and $\mathrm{N}$ large enough, $\partial \hat{\pi}_{2}^{R} / \partial N>\partial \hat{\pi}_{2}^{P} / \partial N$

This shows that if $N$ is sufficiently large, then an increase in $N$ leads to a greater increase in the bank's expected profit from $R$ than from $P$. Hence, the cut-off $\hat{r}_{2}^{s}\left(C_{i}, N\right)$ decreases for any $C_{i}$, giving us $\hat{r}_{2}^{s}\left(C_{i}, n_{0}\right)>\hat{r}_{2}^{s}\left(C_{i}, n_{0}+n_{1}\right)>\hat{r}_{2}^{s}\left(C_{i}, N\right)$

This implies that for a particular realization of $N$, say $N_{1}$, we will have only banks that realized $C_{i}=0$ prefer $R$ over $P$ as $r_{2}^{s}>\hat{r}_{2}^{s}\left(0, N_{1}\right)$, but $r_{2}^{s}<\hat{r}_{2}^{s}\left(\underline{C}, N_{1}\right)$. In this case, $n_{0}$ banks will invest in $R$ at $t=2$ and $N_{1}-n_{0}$ banks will invest in $P$. Relatively small increases in $N$ beyond $N_{1}$ will leave these inequalities unchanged. However, at a sufficiently higher $N$, say $N_{2}>N_{1}$, we will have $r_{2}^{s}>\hat{r}_{2}^{s}\left(\underline{C}, N_{2}\right)$, so now $n_{0}+n_{1}$ banks will invest in $R$ and the rest will invest in $P$. Then these inequalities will remain unchanged for small increases in $N$ beyond $N_{2}$, but for a sufficiently large $N_{3}>N_{2}$, we will have $r_{2}^{s}>\hat{r}_{2}^{s}\left(\bar{C}, N_{3}\right)$, and then all $N_{3}$ banks will switch to $R$ loans.

Thus, it has been proven that the expected number of banks investing in $R$ is non-decreasing in $N$, and for $N$ sufficiently high, all banks invest in $N$.

\section{Proof of Proposition 6:}

The proof is straightforward, given earlier results. With a $P$ loan, if investors learn that the loan repayment probability is exogenous, they view the success probability as $[r+[1-r] b]$ rather than $\left[r_{2}^{s}+\left[1-r_{2}^{s}\right] b\right]$, with $r_{2}^{s}>r$. However, it is still preferable for investors to continue funding $P$ rather than liquidating. However, with $R$, recognition that the true probability is $r q$ rather than $r_{2}^{s} q$ causes investors to liquidate. 
It has already been shown earlier that an increase in $r_{2}^{s}$ leads to an increase in the expected number of banks investing in $R$ (see Proposition 5). Thus, if investors learn that the loan repayment probability of $R$ is exogenous, then these banks are liquidated, implying that an increase in $r_{2}^{s}$ leads to an increase in the expected number of banks that are liquidated.

Proof of Lemma 5: The proof is similar to that of Lemma 2 and therefore omitted for space reasons.

\section{Proof of Proposition 7:}

If the $\lambda$ shock is transitory, then the posterior belief about the bank being of type $\tau$ at the end of the period, at date $t+2$, remains the same as the posterior belief at the beginning of the period, date $t$. Thus, if a bank that was liquidated at date $t+1$ can be revived, it can make the same risky loan at $t+2$ that it made at $t$. If the $\lambda$ shock is permanent, then the posterior belief about the repayment probability of the $R$ loan drops to $r q$ in all subsequent time periods, so a risky loan cannot be financed since $r q X_{R}<1$.

\section{Proof of Proposition 8:}

From (47) it follows that the probability of repayment on a $P$ loan satisfies:

$\lim _{\lambda \rightarrow 0}\{\lambda[r+(1-r) b]+[1-\lambda] b\}=b$.

Since the probability of repayment on the $P$ loan is continuous in $\lambda$, and $b X_{P}<1$, it follows that the bank's expected profit on the $P$ loan will be 0 ignoring $\Psi$, and $-\Psi<0$ if $\Psi$ is included. Thus, the bank does not make a $P$ loan. This is the case in which the bank is unwilling to invest in the $P$ loan and investors are unwilling to find it.

For a higher value of $\lambda$, say $\lambda^{*}>0$, repayment probability may satisfy $\left\{\lambda^{*}[r+(1-r) b]+\left[1-\lambda^{*}\right] b\right\} X_{P}=1$, in which case investors will be willing to fund the $P$ loan. But the bank's expected profit at $\lambda^{*}$ will be $-\Psi<0$, so the bank will not lend even though investors are willing to fund it. The repayment probability on the $\mathrm{R}$ loan will be viewed by the bank as 0 at any $\lambda \leq \lambda^{*}$, so again, the bank's expected profit is $-\Psi<0$. Thus, no lending occurs. 


\section{REFERENCES}

Acharya, Viral, V., Thomas F. Cooley, Matthew P. Richardson, and Ingo Walter, Regulating Wall St.: The DoddFrank Act and the New Architecture of Global Finance, John Wiley \& Sons, Inc., 2011.

Allen, Franklin, Ana Babus, and Elena Carletti, “Asset Commonality, Debt Maturity, and Systemic Risk", Wharton Financial Institutions Center Working Paper 10-30, 2010, forthcoming, Journal of Financial Economics.

Allen, Franklin, and Elena Carletti, "Credit Risk Transfer and Contagion”, Journal of Monetary Economics 53, 2006, pp. 89-111.

Allen, Franklin, and Elena Carletti, "Mark-to-Market Accounting and Cash-in-the-Market Pricing”, Journal of Accounting and Economics 45, 2008, pp. 358-378.

Allen, Franklin, and Douglas Gale, "Bubbles and Crises", Economic Journal 110, 2000a, pp. 236-255.

Allen, Franklin, and Douglas Gale, "Financial Contagion”, Journal of Political Economy 108, 2000b, pp. 1-33.

Allen, Franklin, and Gale, Douglas, Understanding Financial Crises, Oxford University Press, 2007.

Allen, Franklin, and Douglas Gale, “An Introduction to Financial Crises”, in Financial Crises (eds: Allen and Gale) in The International Library of Critical Writings in Economics 218 (series editor: Mark Blaug), 2008, Edward Elgar.

Barth, James, Gerald Caprio, and Ross Levine, The Guardians of Finance: Making them Work For Us, MIT Press, forthcoming.

Bebchuk, Lucian and Joel M. Fried, "Paying for Long-Term Performance", University of Pennsylvania Law Review 158, 2010, pp. 1915-1960.

Berger, Allen N., and Christa H.S. Bouwman, "How Does Capital Affect Bank Performance During Financial Crises?” Working Paper \#11-36, Wharton Financial Institutions Research Center, 2011.

Biais, Bruno, Jean-Charles Rochet, and Paul Woolley, "The Lifecycle of the Financial Sector and Other Speculative Industries", paper presented at the $3^{\text {rd }}$ Banco de Portugal Conference on Financial Intermediation, June 2627, 2009, Vale do Lobo, Algarve, Portugal.

Boot, Arnoud W.A., and Anjan V. Thakor, "Self-Interested Bank Regulation," American Economic Review 83-2, May 1993, pp. 206-212.

Boyd, John, Sungkyu Kwak, and Bruce Smith, “The Real Output Losses Associated with Modern Banking Crises”, Journal of Money, Credit and Banking 37, 2005, pp. 977-999.

Caballero, Ricardo, "Macroeconomics After the Crisis: Time to Deal with the Pretense-of-Knowledge Syndrome", The Journal of Economic Perspectives 24-4, Fall 2010, pp. 85-102.

Caballero, Ricardo, and Alp Simsek, "Fire Sales in a Model of Complexity", MIT Working Paper, July 2010.

Chan, Yuk-Shee, Stuart Greenbaum, and Anjan V. Thakor, “Is Fairly-Priced Deposit Insurance Possible?” Journal of Finance 47-1, March 1992, pp. 227-246.

De Jonghe, Olivier, "Back to the Basics in Banking? A Micro-Analysis of Banking System Stability", Journal of Financial Intermediation 19-3, July 2010, pp. 387-417. 
Fahlenbrach, Rüdiger, and Rene M. Stulz, "Bank CEO Incentives and the Credit Crisis", Journal of Financial Economics, 99-1, 2011, pp. 11-26.

Gennaioli, Nicola, Andrei Shleifer, and Robert Vishny, "Financial Innovation and Financial fragility”, forthcoming, Journal of Financial Economics.

Hall, Robert, "Why Does the Economy Fall to pieces After a Financial Crisis?", Journal of Economic Perspectives 24-4, Fall 2011, pp. 3-20.

Holmstrom, Bengt, and Jean Tirole, "Financial Intermediation, Loanable Funds, and the Real Sector", Quarterly Journal of Economics 112, 1997, pp. 663-691.

Huang, Rocco, and Lev Ratnovski, "The Dark Side of Bank Wholesale Funding", Journal of Financial Intermediation 20-2, April 2011, pp. 248-263.

Independent Evaluation Office of the International Monetary Fund, "IMF Performance in the Run-Up to the Financial and Economic Crisis: IMF Surveillance in 2-004-07”, International Monetary Fund, 2011.

Kane, Edward, "Principal-Agent Problems in S\&L Salvage”, Journal of Finance 45, July 1990, pp. 755-764.

Kindleberger, Charles P., Manias, Panics and Crashes: A History of Financial Crises, John Wiley \& Sons, Inc., 1978.

Litan, Robert E., and Martin N. Bailey, "Fixing Finance: A Roadmap for Reform", Initiative on Business and Public Policy at Brookings, February 2009.

Reinhart, Carmen M., and Kenneth Rogoff, "Is the 2007 U.S. Sub-Prime Financial Crisis So Different? An International Historical Comparison", American Economic Review 98-2, 2008, pp. 339-344.

Rochet, Jean-Charles, Why are There So Many Banking Crises? The Politics and Policy of Bank Regulation, 2008, Princeton University Press.

Shleifer Andrei, and Robert W. Vishny, "Unstable Banking”, Journal of Financial Economics 97, 2010, pp. 306318.

Stiglitz, Joseph, E. Free Fall, W. W. Norton and Company, New York, 2010.

Thakor, Anjan V., "Incentives to Innovate and Financial Crises, Journal of Financial Economics 103-1, January 2012, pp. 130-148.

Wagner, Wolf, "Diversification at Financial Intermediaries and Systemic Crises", Journal of Financial Intermediation 19-3, July 2010, pp. 373-386.

Whitehouse, Mark, “Economists' Grail: A Post-Crash Model”, The Wall Street Journal, Tuesday, November 30, 2010. 